\title{
A comparison of methods for measuring relative radical stabilities of carbon-centred radicals $\dagger \dagger$
}

\author{
Michelle L. Coote, ${ }^{a}{ }^{a}$ Ching Yeh Lin, ${ }^{a}$ Athelstan L. J. Beckwith ${ }^{a}$ and \\ Andreas A. Zavitsas ${ }^{b}$
}

Received 4th March 2010, Accepted 13th May 2010

DOI: $10.1039 / \mathbf{c 0 0 3 8 8 0 f}$

This article discusses and compares various methods for defining and measuring radical stability, including the familiar radical stabilization energy (RSE), along with some lesser-known alternatives based on corrected carbon-carbon bond energies, and more direct measures of the extent of radical delocalisation. As part of this work, a large set of $\mathrm{R}-\mathrm{H}, \mathrm{R}-\mathrm{CH}_{3}, \mathrm{R}-\mathrm{Cl}$ and $\mathrm{R}-\mathrm{R}$ BDEs $\left(\mathrm{R}^{\bullet}={ }^{\bullet} \mathrm{CH}_{2} \mathrm{X},{ }^{\bullet} \mathrm{CH}\left(\mathrm{CH}_{3}\right) \mathrm{X},{ }^{\bullet} \mathrm{C}\left(\mathrm{CH}_{3}\right)_{2} \mathrm{X}\right.$ and $\mathrm{X}=\mathrm{H}, \mathrm{BH}_{2}, \mathrm{CH}_{3}, \mathrm{NH}_{2}, \mathrm{OH}, \mathrm{F}, \mathrm{SiH}_{3}, \mathrm{PH}_{2}, \mathrm{SH}, \mathrm{Cl}, \mathrm{Br}$, $\mathrm{N}\left(\mathrm{CH}_{3}\right)_{2}, \mathrm{NHCH}_{3}, \mathrm{NHCHO}, \mathrm{NHCOCH}_{3}, \mathrm{NO}_{2}, \mathrm{OCF}_{3}, \mathrm{OCH}_{2} \mathrm{CH}_{3}, \mathrm{OCH}_{3}, \mathrm{OCHO}, \mathrm{OCOCH}_{3}$, $\mathrm{Si}\left(\mathrm{CH}_{3}\right)_{3}, \mathrm{P}\left(\mathrm{CH}_{3}\right)_{2}, \mathrm{SC}\left(\mathrm{CH}_{3}\right)_{2} \mathrm{CN}, \mathrm{SCH}_{2} \mathrm{COOCH}_{3}, \mathrm{SCH}_{2} \mathrm{COOCH}_{3}, \mathrm{SCH}_{2} \mathrm{Ph}, \mathrm{SCH}_{3}, \mathrm{SO}_{2} \mathrm{CH}_{3}, \mathrm{~S}(\mathrm{O}) \mathrm{CH}_{3}$, $\mathrm{Ph}, \mathrm{C}_{6} \mathrm{H}_{4}-p \mathrm{CN}, \mathrm{C}_{6} \mathrm{H}_{4}-p \mathrm{NO}_{2}, \mathrm{C}_{6} \mathrm{H}_{4}-p \mathrm{OCH}_{3}, \mathrm{C}_{6} \mathrm{H}_{4}-p \mathrm{OH}, \mathrm{CF}_{2} \mathrm{CF}_{3}, \mathrm{CF}_{2} \mathrm{H}, \mathrm{CF}_{3}, \mathrm{CCl}_{2} \mathrm{H}, \mathrm{CCl}_{3}, \mathrm{CH}_{2} \mathrm{Cl}$, $\mathrm{CH}_{2} \mathrm{~F}, \mathrm{CH}_{2} \mathrm{OH}, \mathrm{CH}_{2} \mathrm{Ph}$, cyclo- $\mathrm{CH}\left(\mathrm{CH}_{2}\right)_{2}, \mathrm{CH}_{2} \mathrm{CH}=\mathrm{CH}_{2}, \mathrm{CH}_{2} \mathrm{CH}_{3}, \mathrm{CH}\left(\mathrm{CH}_{3}\right)_{2}, \mathrm{C}\left(\mathrm{CH}_{3}\right)_{3}, \mathrm{C} \equiv \mathrm{CH}$, $\left.\mathrm{CH}=\mathrm{CH}_{2}, \mathrm{CH}=\mathrm{CHCH}_{3}, \mathrm{CHO}, \mathrm{CN}, \mathrm{COCH}_{3}, \mathrm{CON}\left(\mathrm{CH}_{2} \mathrm{CH}_{3}\right)_{2}, \mathrm{CONH}_{2}, \mathrm{CONHCH}_{3}, \mathrm{COOC} \mathrm{CH}_{3}\right)_{3}$, $\mathrm{COOCH}_{2} \mathrm{CH}_{3}, \mathrm{COOCH}_{3}, \mathrm{COOH}, \mathrm{COPh}$ ), and associated radical stability values are calculated using the high-level ab initio molecular orbital theory method G3(MP2)-RAD. These are used to compare the alternative radical stability schemes and illustrate principal structure-reactivity trends.

${ }^{a}$ ARC Centre of Excellence for Free-Radical Chemistry and Biotechnology, Research School of Chemistry, Australian National University, Canberra, ACT 0200, Australia.

E-mail:mcoote@rsc.anu.edu.au

${ }^{b}$ Department of Chemistry and Biochemistry, Long Island University, University Plaza, Brooklyn, New York 11201, USA

$\dagger$ In fond memory of our friend and colleague, Emeritus Professor Athel Beckwith FAA, FRACI, FRS and in recognition of his many distinguished contributions to chemistry. Athel died on May $15^{\text {th }}, 2010$.

$\ddagger$ Electronic supplementary information (ESI) available: Available experimental data corresponding to the BDEs in Table 1 (Table S1). $\mathrm{BDE}\left[\mathrm{CH}_{3}-\mathrm{CH}_{2} \mathrm{X}\right]$ obtained by eqn (9), using $\chi\left[\mathrm{CH}_{2} \mathrm{X}\right]$ obtained only from eqn (10), compared to the corresponding G3(MP2)-RAD values (Table S2). A comparison of B3-LYP/6-31G(d) and G3(MP2)-RAD electron affinities and ionisation potentials (Table $\mathrm{S} 3$ ); $\mathrm{RSE}_{\mathrm{V}}$ values for ${ }^{\bullet} \mathrm{CH}_{2} \mathrm{X},{ }^{\bullet} \mathrm{CH}\left(\mathrm{CH}_{3}\right) \mathrm{CH}_{3}$ and ${ }^{\bullet} \mathrm{C}\left(\mathrm{CH}_{3}\right)_{2} \mathrm{X}$ obtained via the various possible approaches (Tables S4-S6). Complete optimized geometries of all species (Table S7). See DOI: 10.1039/c003880f

\section{Introduction}

Carbon-centred radicals play a vital role in healthy enzyme function as well as ageing and disease. They are also important intermediates in a wide variety of chemical processes, including combustion, polymerisation and many organic transformations. A detailed understanding of how these processes are affected by the substitution pattern of the reagents is crucial to the development of techniques for manipulating and controlling their outcome. Thermodynamic measures of relative radical stabilities can greatly simplify the analysis of structure-reactivity trends by helping to decouple the contributions to the overall reaction energy from the radical and non-radical species. However, defining and measuring radical stability is not

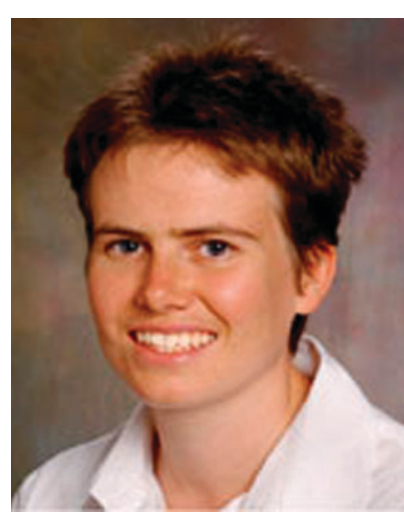

Michelle L. Coote
Michelle Coote received her BSC (Hons) in industrial chemistry from the University of New South Wales (1995), followed by a PhD in polymer chemistry (2000) under the supervision of Tom Davis. Following postdoctoral work with Randal Richards at the University of Durham, UK, she joined the Research School of Chemistry, Australian National University, in 2001, where she is now leader of the Computer-Aided Chemical Design research group, and a Chief Investigator of the ARC Centre of Excellence for Free-Radical Chemistry and Biotechnology. She has published extensively in the fields of free-radical polymerization kinetics, radical chemistry and computational quantum chemistry.

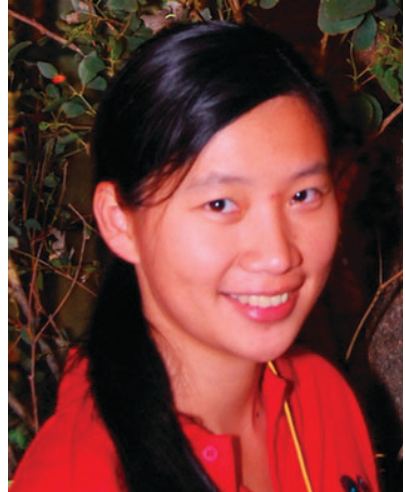

Ching Yeh Lin
Ching Yeh Lin received her $B S c$ in Applied Chemistry from National Chiao Tung University, Taiwan, in 2002. Subsequently, she received her PhD in Theoretical Quantum Chemistry under the supervision of Prof. Peter Gill from the Australian National University in 2006. She has worked as a postdoctoral researcher and now a research officer in Computational Quantum Chemistry with Assoc. Prof. Michelle Coote, focusing on controlled free radical polymerisation. She is also a member of the ARC Centre of Excellence for Free-Radical Chemistry and Biotechnology. 
straightforward, and several alternative schemes have been proposed. The aim of the present work is to examine and compare some of the leading methods for measuring relative radical stability with a view to identifying their scope and limitations.

In general terms, the stability or reactivity of a species refers to its propensity to undergo chemical reactions, as assessed either on a thermodynamic basis or a kinetic basis. For radicals, the thermodynamic stability is typically termed the stabilization energy, whilst the kinetic stability is typically termed the persistence. ${ }^{1}$ Strictly speaking, the stability of a species can only be unambiguously defined in the context of a specific balanced chemical reaction. However, through careful choice of the defining reaction, it is sometimes possible to use stabilities, as measured for one class of reactions, to help predict the kinetic and thermodynamic behaviour of those species in other types of chemical reactions. ${ }^{2}$

The standard radical stabilization energy (RSE) $)^{1,3}$ is the most commonly used thermodynamic measure of relative radical stability. For a carbon-centred radical $\mathbf{R}^{\bullet}$, the RSE is defined as the enthalpy change $(\Delta H)$ of the following isodesmic reaction (1):

$$
\mathrm{R}^{\bullet}+\mathrm{H}-\mathrm{CH}_{3} \rightarrow \mathrm{R}-\mathrm{H}+{ }^{\bullet} \mathrm{CH}_{3}
$$

In essence, one compares the energy of the radical $\mathrm{R}^{\bullet}$ to a reference species ${ }^{\circ} \mathrm{CH}_{3}$, and balances the reaction using the corresponding closed shell species. An alternative (and completely equivalent) method for representing the standard $\mathrm{RSE}$ is as the difference of the corresponding $\mathrm{R}-\mathrm{H}$ and $\mathrm{CH}_{3}-\mathrm{H}$ bond dissociation enthalpies (BDEs).

$$
\mathrm{RSE}=\mathrm{BDE}\left[\mathrm{CH}_{3}-\mathrm{H}\right]-\mathrm{BDE}[\mathrm{R}-\mathrm{H}]
$$

Defined in this way, when the RSE for radical $\mathrm{R}^{\bullet}$ is positive, $\mathrm{R}^{\bullet}$ is said to be more stabilized than ${ }^{\circ} \mathrm{CH}_{3}$; if the RSE is negative, $\mathrm{R}^{\bullet}$ is said to be less stabilized. ${ }^{4}$
Strictly speaking, the standard RSE measures the thermodynamic stability of the $\mathrm{R}^{\bullet}$ radical (relative to ${ }^{\circ} \mathrm{CH}_{3}$ ) toward hydrogen atom transfer reactions only, and includes contributions from the relative stabilities of the radicals, and the relative stabilities of the $\mathrm{C}-\mathrm{H}$ bonds in $\mathrm{R}-\mathrm{H}$ and $\mathrm{CH}_{3}-\mathrm{H}$ molecules that balance the reaction. However, it is normally assumed that, since hydrogen is small and makes relatively non-polar bonds to carbon, the differences in stability of the $\mathrm{C}-\mathrm{H}$ bonds in $\mathrm{R}-\mathrm{H}$ and $\mathrm{CH}_{3}-\mathrm{H}$ are minor and therefore cancel from the overall reaction enthalpy. Thus, for carbon-centred radicals at least, the RSE is generally regarded as a measure of the relative stabilities of the radicals alone. In support of this assumption it is worth noting that trends in RSEs have been successfully analysed in terms of arguments involving only the radical species itself, ${ }^{5}$ and the resulting insights have been used successfully in many studies to predict the stability and reactivity of radicals in other chemical reactions such as radical addition to alkenes. ${ }^{6}$

Nonetheless it is worth emphasizing that the use of RSEs to measure radical stability is based on an assumption (i.e., that the stabilities of the $\mathrm{C}-\mathrm{H}$ bonds of the closed shell species used to balance the reaction are very similar in $\mathrm{R}-\mathrm{H}$ and $\mathrm{CH}_{3}-\mathrm{H}$ ), and this assumption may occasionally break down, particularly if polar and/or steric effects in $\mathrm{R}$ are significant. ${ }^{7,8}$ As an illustration, Fig. 1 shows the relative stabilities of the alkyl radical series Me, Et, $i$-Pr and $t$-Bu, as calculated using the standard RSE, and alternative definitions in which other types of closed shell species (i.e. $\mathrm{R}-\mathrm{X}$ and $\mathrm{CH}_{3}-\mathrm{X}$, where $\mathrm{X}=\mathrm{CH}_{3}, \mathrm{OH}, \mathrm{F}$ ) are used to balance the reaction instead. ${ }^{9}$ As is clear from this graph, even the qualitative ordering of the RSEs is highly sensitive to the type of closed shell species used to balance the reaction, implying that the contribution of the differences in stability of the $\mathrm{R}-\mathrm{X}$ and $\mathrm{CH}_{3}-\mathrm{X}$ bonds to the reaction energy is not insignificant.

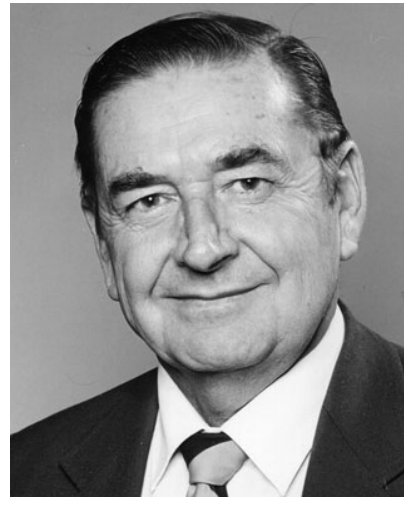

Athelstan L. J. Beckwith
Athel Beckwith graduated as BSc (Hons) at the University of Western Australia and as DPhil from Oxford with $W$. A. Waters before joining CSIRO Melbourne as a Research Scientist. He then moved to the University of Adelaide first as lecturer and later as Professor of Organic Chemistry. In 1981 he joined the Australian National University as Professor of Chemistry, where he later served as Dean of the Research School of Chemistry, and as Emeritus Professor. He has published extensively on the chemistry of organic free radicals and other reactive intermediates and has participated in joint research at Imperial College, York, Oxford, Ottawa and Freiberg. He has been the recipient of many prestigious scientific awards and was elected to the Fellowship of the Australian Academy of Science in 1974 and the Royal Society in 1987.

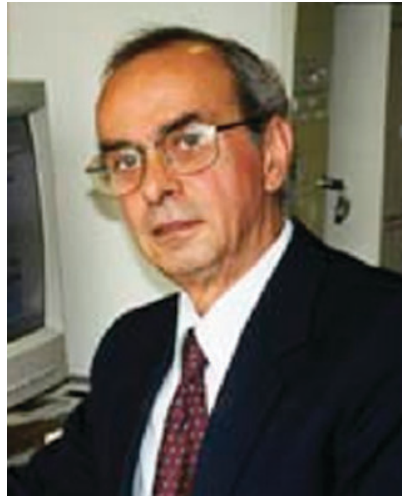

Andreas A. Zavitsas
Born in Athens, Greece, Zavitsas received the $B S$ at the City College of NY and the PhD at Columbia University with Cheves Walling. After two years with the US Atomic Energy Commission and three years with the Monsanto Company, he joined Long Island University, Brooklyn, NY, where he is professor of chemistry. His publications are on organic free radicals, isotope effects, phenolic resins, chemical kinetics, potential energy curves, thermodynamics of organic compounds, and behaviors of aqueous solutions. He has been visiting research fellow at the Australian National University and visiting research professor at the National Research Council in Bologna, Italy. 


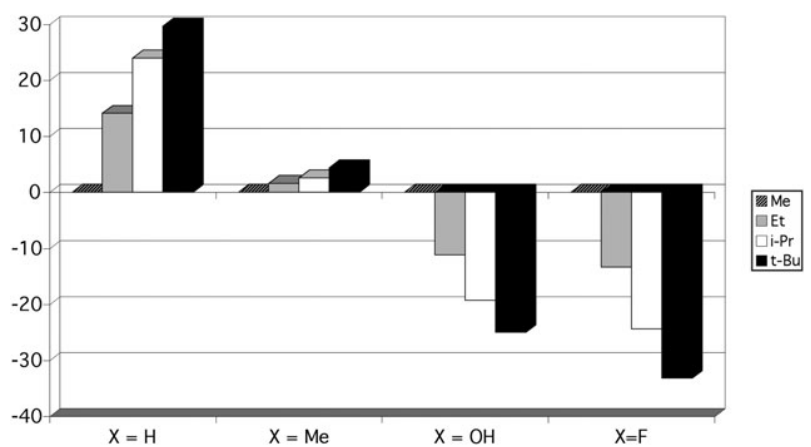

Fig. 1 RSEs $\left(0 \mathrm{~K} ; \mathrm{kJ} \mathrm{mol}^{-1}\right)$ for the series $\mathrm{Me}$, Et, i-Pr and t-Bu as calculated using various reactions of the general form: $\mathrm{R}^{\bullet}+\mathrm{X}-\mathrm{CH}_{3} \rightarrow$ $\mathrm{R}-\mathrm{X}+{ }^{\bullet} \mathrm{CH}_{3}$, for $\mathrm{X}=\mathrm{H}, \mathrm{CH}_{3}, \mathrm{OH}$ and $\mathrm{F}$. Data taken from ref. 9 .

In fact, in this example, there is a significant contribution to the RSE from the differences in stability of the $\mathrm{R}-\mathrm{X}$ and $\mathrm{R}-\mathrm{CH}_{3}$ bonds. ${ }^{8,9}$ This is due to the stabilization of $\mathrm{R}-\mathrm{X}$ by resonance between the covalent $(\mathrm{R}-\mathrm{X})$ and ionic forms $\left(\mathrm{R}^{+} \mathrm{X}^{-}\right)$, an effect that increases with the increasing electron donating ability of $\mathrm{R}$ from $\mathrm{Me}<\mathrm{Et}<i$-Pr $<t$-Bu. This increasing stabilization of the bond counters the concurrent increasing stability of the radical that results from hyperconjugative stabilization of the unpaired electron. For electronegative $\mathrm{X}$ groups such as $\mathrm{F}$ and $\mathrm{OH}$, the effect on bond strength is dominant, resulting in a decrease in the measured RSE from $\mathrm{Me}$ to $t$ - $\mathrm{Bu}$; for the less electronegative $\mathrm{X}$ groups (in this case $\mathrm{H}$ and $\mathrm{CH}_{3}$ ) the effect on radical stability dominates and the expected increase in RSE from Me to $t$-Bu is observed. Whilst the standard RSE (i.e., $\mathrm{X}=\mathrm{H}$ ) represents a limiting case for which the polar contribution to bond strength is smallest, this does not necessarily imply that effects of bond dipoles are absent or that they may not be complicating RSE measurements for other radicals.

The contribution of steric effects in the $\mathrm{R}-\mathrm{H}$ reference compounds to trends in radical stabilization energies has also been the subject of considerable recent debate. For example, it has been suggested on the basis of a group additivity scheme that the trends in $\mathrm{R}-\mathrm{H}$ BDEs for the simple $\mathrm{Me}, \mathrm{Et}, i$-Pr and $t$-Bu series could be attributed to relief of 1,3 repulsive $\mathrm{H} / \mathrm{H}$, $\mathrm{H} / \mathrm{CH}_{3}$ and $\mathrm{CH}_{3} / \mathrm{CH}_{3}$ interactions in the closed-shell compounds. ${ }^{10,11}$ This proposal was later challenged by Wodrich and Schleyer, ${ }^{12}$ who, on the basis of a simpler group additivity scheme, supported the traditional view that the trends in $\mathrm{R}-\mathrm{H}$ BDEs arise from hyperconjugative stabilization of the radical species. The importance of hyperconjugation was also supported by Ingold and DiLabio ${ }^{13}$ on the basis of an analysis of EPR coupling constants for the radical species. Nonetheless, relief of steric effects would be expected to play an important role in the trends in $\mathrm{R}-\mathrm{X}$ BDEs when $\mathrm{X}$ is bulky, and have, for example, been implicated in the differences between relative $\mathrm{R}-\mathrm{H}$ and $\mathrm{R}-\mathrm{CH}_{3}$ BDEs. ${ }^{14}$ Whilst the $\mathrm{R}-\mathrm{H}$ BDEs represent a limiting case, where steric effects might be expected to be smallest, their participation cannot be wholly ruled out.

Given these problems, alternative definitions of the RSE have been proposed. For example, Rüchardt et al. ${ }^{15}$ have measured the radical stabilization energies (which we will label $\mathrm{RSE}_{\mathrm{C}-\mathrm{C}}$ ) of various $\mathrm{R}^{\bullet}$ radicals from corrected $\mathrm{R}-\mathrm{R}$ BDEs.
The advantage of using $\mathrm{R}-\mathrm{R}$ in place of $\mathrm{R}-\mathrm{H}$ is that polar effects in the reference compound are eliminated; the disadvantage is that corrections for steric strain in $\mathrm{R}-\mathrm{R}$ are instead required. The exact application of this method depends on the substitution pattern of the radical involved but may be loosely generalized as follows:

$$
\mathrm{RSE}_{\mathrm{C}-\mathrm{C}}=\frac{1}{2}\left(\mathrm{BDE}[\mathrm{R}-\mathrm{R}]-\Delta H^{\ddagger}[\text { reference }]\right)-\Delta H_{\mathrm{g}}
$$

In this equation, $\Delta H_{\mathrm{g}}$ is a correction term for geminal interactions (or other interactions, as relevant) in the parent $\mathrm{R}-\mathrm{R}$ compound; these are estimated separately from rotational barriers and/or other types of model reactions as relevant. The term $\Delta H^{\ddagger}$ [reference] measures the energy of the $\mathrm{C}-\mathrm{C}$ bond in the corresponding unsubstituted reference compound, and includes corrections for the release of steric strain during dissociation of $\mathrm{R}-\mathrm{R}$. This steric strain correction $\left(D_{\mathrm{s}}\right)$ is calculated as follows:

$$
D_{\mathrm{S}}=H_{\mathrm{S}}(\mathrm{R}-\mathrm{R})-2 H_{\mathrm{S}}(\mathrm{R}-\mathrm{H})
$$

where $H_{\mathrm{s}}$ is the strain energy, as calculated via MM2 force field calculations of the compounds $\mathrm{R}-\mathrm{R}$ and $\mathrm{R}-\mathrm{H} .{ }^{15}$ The $D_{\mathrm{s}}$ value is then used to adjust $\Delta H^{\ddagger}$ [reference] for the additional steric strain in $\mathrm{R}-\mathrm{R}$. For example, in a study of the $\mathrm{RSE}_{\mathrm{C}-\mathrm{C}}$ values of a series of $\alpha$-amino- $\alpha$-carbonylmethyl radicals, tetraalkyl ethanes were selected as the reference compounds. For tetraalkyl ethanes, a linear correlation between $\Delta H^{\ddagger}$ for homolysis and $D_{\mathrm{s}}$ had been obtained in an earlier study: ${ }^{16}$

$$
\Delta H^{\ddagger}[\text { alkane }]=73.8-0.76 D_{\mathrm{s}}\left[\mathrm{kcal} \mathrm{mol}^{-1}\right]
$$

Thus, to calculate $\mathrm{RSE}_{\mathrm{C}-\mathrm{C}}$ for radical $\mathrm{R}^{\bullet}$, the value of $D_{\mathrm{s}}$ for $\mathrm{R}-\mathrm{R}$ is substituted into eqn (5) so as to obtain $\Delta H^{\ddagger}$ [alkane], which is then substituted into eqn (3).

More recently, one of us has designed an alternative definition of the radical stabilization energy (which we will label $\mathrm{RSE}_{\mathrm{Z}}$ ) that also is based on corrected R-R BDEs. ${ }^{17}$ However, this method does not rely on MM2-derived strain energies or existing relationships between these energies and kinetic data, and is therefore more easily applied to new systems. For carbon-centred radicals $\left(\mathrm{R}^{\bullet}\right), \mathrm{RSE}_{\mathrm{Z}}$ is calculated as follows:

$$
\mathrm{RSE}_{\mathrm{Z}}=\frac{1}{2}\left(\mathrm{BDE}\left[\mathrm{CH}_{3}-\mathrm{CH}_{3}\right]-\mathrm{BDE}[\mathrm{R}-\mathrm{R}]^{*}\right)
$$

where: $\mathrm{BDE}[\mathrm{R}-\mathrm{R}]^{*}$ is the 'strain-free' $\mathrm{R}-\mathrm{R}$ bond dissociation energy of the compound $\mathrm{R}-\mathrm{R}$ and $\mathrm{BDE}\left[\mathrm{CH}_{3}-\mathrm{CH}_{3}\right]$ is the corresponding $\mathrm{C}-\mathrm{C}$ bond dissociation energy of ethane (assumed to be strain-free). The $\mathrm{BDE}[\mathrm{R}-\mathrm{R}]^{*}$ represents the hypothetical $\mathrm{BDE}$ that would be obtained if there were no steric (or other) special interactions between the R groups, and is estimated by application of Pauling's electronegativity equation ${ }^{18}$ to known values of the BDEs for $\mathrm{R}-\mathrm{OH}, \mathrm{R}-\mathrm{CH}_{3}, \mathrm{CH}_{3}-\mathrm{CH}_{3}, \mathrm{CH}_{3}-\mathrm{OH}$ and $\mathrm{HO}-\mathrm{OH}$ as follows.

Pauling's electronegativity equation ${ }^{18}$ relates the BDE of a compound $\mathrm{A}-\mathrm{B}$ to the average inherent covalent bonding energy of $\mathrm{A}$ and $\mathrm{B}$ (measured as the average of the BDEs of $\mathrm{A}-\mathrm{A}$ and $\mathrm{B}-\mathrm{B}$ ) and an empirically-based polar term (measured as the square of the difference in the electronegativities $(\chi)$ of $\mathrm{A}$ and $\mathrm{B}, \Delta \chi^{2}=(\chi[\mathrm{A}]-\chi[\mathrm{B}])^{2}$.

$D[\mathrm{~A}-\mathrm{B}]=\frac{1}{2}\left(\mathrm{BDE}[\mathrm{A}-\mathrm{A}]^{*}+\mathrm{BDE}[\mathrm{B}-\mathrm{B}]^{*}\right)+96 \Delta \chi^{2}\left[\mathrm{~kJ} \mathrm{~mol}^{-1}\right]$ 
In this equation, the factor 96 is a proportionality constant for units of $\mathrm{kJ} \mathrm{mol}^{-1}$; for $\mathrm{kcal} \mathrm{mol}^{-1}$ the constant is 23 . The A-A and $\mathrm{B}-\mathrm{B}$ BDEs in this equation are assumed to be free from contributions from steric effects, and other specific interactions (hydrogen bonding, anomeric effects, etc). The electronegativity was defined by Pauling as 'the attraction of a neutral atom in a stable molecule for electrons', and an arbitrary scale was established for atoms, with fluorine being assigned a value of 4.0 , oxygen 3.5 , carbon 2.5 , etc. By taking a reference value of $\chi[\mathrm{OH}]=3.500$, electronegativity values for any functional group $\mathrm{R}$ can be calculated by substituting known values for the BDEs of $\mathrm{R}-\mathrm{R}, \mathrm{R}-\mathrm{OH}$, and $\mathrm{OH}-\mathrm{OH}$ into eqn (7). Values of the strain-free $\mathrm{R}-\mathrm{R}$ BDE (i.e., $\mathrm{BDE}[\mathrm{R}-\mathrm{R}]^{*}$ ) and $\chi[\mathrm{R}]$ are obtained by satisfying the following two equations simultaneously (in $\mathrm{kJ} \mathrm{mol}^{-1}$ ):

$$
\begin{aligned}
D[\mathrm{R}-\mathrm{OH}]= & \frac{1}{2}\left(\mathrm{BDE}[\mathrm{R}-\mathrm{R}]^{*}+\mathrm{BDE}[\mathrm{HO}-\mathrm{OH}]\right) \\
& +96(\chi[\mathrm{R}]-\chi[\mathrm{HO}])^{2}\left[\mathrm{~kJ} \mathrm{~mol}^{-1}\right]
\end{aligned}
$$

$\chi\left[\mathrm{CH}_{3}\right]$ and $\chi[\mathrm{Cl}]$. For the standard RSE, only the $\mathrm{R}-\mathrm{H}$ $\mathrm{BDE}$ is needed in addition to the reference $\mathrm{BDE}\left[\mathrm{CH}_{3}-\mathrm{H}\right]$ value. In addition, the scheme may break down if there are additional specific interactions (such as hydrogen bonding or anomeric effects) affecting the stability of the $\mathrm{R}-\mathrm{CH}_{3}$ or $\mathrm{R}-\mathrm{Cl}$ bonds. Nonetheless, this scheme has been shown to yield chemically intuitive values of relative radical stabilities, and strain energies. ${ }^{17}$ It also has excellent predictive value when used to calculate bond energies for unknown combinations of $\mathrm{R}-\mathrm{X}$ from the corresponding $\mathrm{R}-\mathrm{R}$ and $\mathrm{X}-\mathrm{X}$ BDEs; for example, in the original study, the energies of 117 bonds were predicted to be within $\pm 1.5 \mathrm{kcal} \mathrm{mol}^{-1}$ of experiment. $^{17}$

A related radical stability scheme (which we will label $\mathrm{RSE}_{\mathrm{V}}$ ) has recently been published by de Vleeschouwer et al. ${ }^{19}$ In this scheme the BDE of compound $\mathrm{A}-\mathrm{B}$ is expressed in terms of the stabilities of radicals $\mathrm{A}^{\bullet}$ and $\mathrm{B}^{\bullet}$ and a polar correction as follows:

$$
\mathrm{BDE}[\mathrm{A}-\mathrm{B}]=\left\{\begin{array}{l}
\left(\mathrm{RSE}_{\mathrm{V}}[\mathrm{A}]+\mathrm{RSE}_{\mathrm{V}}[\mathrm{B}]\right)+a \Delta \omega[\mathrm{A}] \Delta \omega[\mathrm{B}] \text { if } \Delta \chi[\mathrm{A}]<0 \text { and } \Delta \chi[\mathrm{B}]<0 \\
\left(\operatorname{RSE}_{\mathrm{V}}[\mathrm{A}]+\operatorname{RSE}_{\mathrm{V}}[\mathrm{B}]\right)+a \Delta \omega[\mathrm{A}] \Delta \omega[\mathrm{B}]+b \Delta \chi[\mathrm{A}] \Delta \chi[\mathrm{B}] \text { otherwise }
\end{array}\right.
$$

$$
\begin{aligned}
D\left[\mathrm{R}-\mathrm{CH}_{3}\right]= & \frac{1}{2}\left(\mathrm{BDE}[\mathrm{R}-\mathrm{R}]^{*}+\mathrm{BDE}\left[\mathrm{CH}_{3}-\mathrm{CH}_{3}\right]\right) \\
& +96\left(\chi[\mathrm{R}]-\chi\left[\mathrm{CH}_{3}\right]\right)^{2}\left[\mathrm{~kJ} \mathrm{~mol}^{-1}\right]
\end{aligned}
$$

In doing this, it is assumed that steric effects (and other specific interactions) are absent from the $\mathrm{R}-\mathrm{CH}_{3}, \mathrm{R}-\mathrm{OH}, \mathrm{HO}-\mathrm{OH}$ and $\mathrm{CH}_{3}-\mathrm{CH}_{3}$ BDEs. Since $\mathrm{OH}$ groups can sometimes undergo specific interactions with $\mathrm{R}$ (such as anomeric effects), in the present work we will actually apply this scheme using $\mathrm{R}-\mathrm{Cl}$ and $\mathrm{Cl}-\mathrm{Cl}$ BDEs in place of the $\mathrm{R}-\mathrm{OH}$ and $\mathrm{HO}-\mathrm{OH}$ BDEs. Using known values of $\chi[\mathrm{Cl}]=3.18$ and $\chi\left[\mathrm{CH}_{3}\right]=2.52,{ }^{17}$ and BDE values calculated by G3(MP2)-RAD (see below) for $\mathrm{R}-\mathrm{CH}_{3}, \mathrm{R}-\mathrm{Cl}, \mathrm{Cl}-\mathrm{Cl}$, and $\mathrm{CH}_{3}-\mathrm{CH}_{3}$, eqn (9) and (10) will be used to obtain $\chi[\mathrm{R}]$ so that $D\left[\mathrm{R}-\mathrm{CH}_{3}\right]$ and $D[\mathrm{R}-\mathrm{Cl}]$ are matched exactly. BDE[R-R]* is then obtained by inserting the $\chi[\mathrm{R}]$ into eqn (9) and (10), hence allowing $\mathrm{RSE}_{Z}$ to be determined by eqn (6).

$$
\begin{aligned}
D[\mathrm{R}-\mathrm{Cl}]= & \frac{1}{2}\left(\mathrm{BDE}[\mathrm{Cl}-\mathrm{Cl}]+\mathrm{BDE}[\mathrm{R}-\mathrm{R}]^{*}\right) \\
& +96(\chi[\mathrm{R}]-\chi[\mathrm{Cl}])^{2}\left[\mathrm{~kJ} \mathrm{~mol}{ }^{-1}\right]
\end{aligned}
$$

Like $\mathrm{RSE}_{\mathrm{C}-\mathrm{C}}$, the $\mathrm{RSE}_{\mathrm{Z}}$ scheme offers significant advantages over the traditional RSE. In particular, by basing the $\mathrm{RSE}_{\mathrm{Z}}$ on the difference of $\mathrm{R}-\mathrm{R}$ and $\mathrm{CH}_{3}-\mathrm{CH}_{3}$ BDEs, the contribution to $\mathrm{RSE}_{\mathrm{Z}}$ from dipole interactions in the closed-shell compounds is eliminated. This becomes particularly important when the scheme is applied to non-carbon-centred radicals. Although steric effects are likely to be much more significant in $\mathrm{R}-\mathrm{R}$ BDEs compared with $\mathrm{R}-\mathrm{H}$ BDEs, these contributions are also minimized by using the strain-free BDEs in place of the true ones. In obtaining these strain-free BDEs, the scheme does become dependent on Pauling's semi-empirical electronegativity equation and requires additional information to implement. For example, to obtain an $\mathrm{RSE}$ for some new radical $\mathrm{R}^{\bullet}$, one would need to know the $\mathrm{R}-\mathrm{Cl}$ and $\mathrm{R}-\mathrm{CH}_{3}$ BDEs in addition to the reference values of $\mathrm{BDE}[\mathrm{Cl}-\mathrm{Cl}], \mathrm{BDE}\left[\mathrm{CH}_{3}-\mathrm{CH}_{3}\right]$,
In this equation, $\Delta \omega[i]=\omega[i]-2$, where $\omega[i]$ is the nucleophilicity index of $i$ in $\mathrm{eV} ; \Delta \chi[i]=\chi[i]-3$, where $\chi[i]$ is the Pauling electronegativity parameter of $i$, as defined above. The nucleophilicity index is calculated from the electronic chemical potential $\mu$ and the chemical hardness $\eta$, which are in turn obtained from the calculated vertical ionization potential (IP) and electron affinity (EA) as follows: ${ }^{20,21}$

$$
\omega=\frac{\mu^{2}}{2 \eta}=\frac{(\mathrm{IP}+\mathrm{EA})^{2}}{8(\mathrm{IP}-\mathrm{EA})}
$$

To calculate the values of $\mathrm{RSE}_{\mathrm{V}}$, de Vleeschouwer et al. ${ }^{19}$ performed a 49-parameter least-squares fit to the known values of the relevant $\mathrm{A}-\mathrm{B}$ BDEs, $\chi$ and $\omega$ values for a set of 47 radicals $\mathrm{A}^{\bullet}$ in combinations with $\mathrm{B}=\mathrm{CH}_{2} \mathrm{OH}, \mathrm{H}$ and $\mathrm{F}$. This yielded $\mathrm{RSE}_{\mathrm{V}}$ values for the 47 radicals and values of $a=-12.88 \mathrm{~kJ} \mathrm{~mol}^{-1} \mathrm{eV}^{-2}$ and $b=-216.50 \mathrm{~kJ} \mathrm{~mol}^{-1}$. Although all originally published $\mathrm{RSE}_{\mathrm{V}}$ values were estimated as fit parameters for an initial training set, subsequent $\mathrm{RSE}_{\mathrm{V}}$ values for some unknown radical $\mathrm{A}^{\bullet}$ can be obtained from a known $\mathrm{A}-\mathrm{B}$ BDE value, provided the $\mathrm{RSE}_{\mathrm{V}}$ value of $\mathrm{B}^{\bullet}$ and all the relevant $\chi$ and $\omega$ values are known.

Both the $\mathrm{RSE}_{\mathrm{Z}}$ and $\mathrm{RSE}_{\mathrm{V}}$ schemes base the calculation of radical stabilization energies on bond energy data that have been explicitly corrected for effects of bond dipoles; however, a key difference is that the $\mathrm{RSE}_{\mathrm{Z}}$ scheme also attempts to minimize other influences on the bond energies (such as steric effects) by basing the actual $\mathrm{RSE}_{\mathrm{Z}}$ calculation on "strain-free" $\mathrm{R}-\mathrm{R}$ BDEs. In contrast, the $\mathrm{RSE}_{\mathrm{V}}$ values are based on $\mathrm{A}-\mathrm{B}$ BDEs for potentially any combination of $\mathrm{A}$ and $\mathrm{B}$, and one might therefore expect this scheme to break down when it is extended to situations where steric, resonance, anomeric and other interactions between A and B are likely. Indeed, when in the original work ${ }^{19}$ the scheme was tested by using the fitted 
$\mathrm{RSE}_{\mathrm{V}}$ values (and associated $\chi$ and $\omega$ values) for the test of radicals $\mathrm{A}^{\bullet}$ to predict $\mathrm{A}-\mathrm{B}$ BDEs for combinations with $\mathrm{B}=\mathrm{CH}_{3}, \mathrm{NF}_{2}, \mathrm{OCH}_{3}, \mathrm{OH}$ and $\mathrm{SH}$, the MAD was quite large $\left(16.4 \mathrm{~kJ} \mathrm{~mol}^{-1}\right)$, with maximum deviations exceeding $70 \mathrm{~kJ} \mathrm{~mol}^{-1}$. These discrepancies may be due in part to known errors in DFT-derived BDE data, ${ }^{22,23}$ as used in constructing the training and test sets for the original study, but may also reflect the varying non-polar contribution to the strength of the $\mathrm{A}-\mathrm{B}$ bond as $\mathrm{A}$ and $\mathrm{B}$ are varied. For both of these reasons, the dependence of this method on the choice and quality of the initial training set may be a potential source of error or bias in the calculated $\mathrm{RSE}_{\mathrm{V}}$ values, particularly when the scheme is extended to very different systems using data from different sources. For this reason, in the present work we will examine two versions of this method, one based on the original parameterisation and one based on re-parameterisation to the present test set of high-level ab initio molecular orbital theory derived BDE data.

The above radical stability schemes all measure the stabilization energy of a radical from its contribution to various bond energies; an alternative approach is to use measurements of the extent of delocalization of the unpaired electron. In essence, it is presumed that since radicals are stabilized by substituents that delocalize the unpaired electron, the more delocalized the unpaired electron, the more stable the radical is likely to be. This phenomenological approach allows one to focus solely on the radical, thereby avoiding complications from substituent effects on the closed-shell reference compounds used to balance the chemical reactions in the other radical stability schemes. However, its potential disadvantage is that it is not necessarily clear that alternative mechanisms of delocalization ( $\pi$-delocalization, hyperconjugation, spin polarization, and anomeric interactions, and combinations thereof) will lead to the same increase in radical stability for the same degree of spin delocalization. ${ }^{24}$ Moreover, it is in any case difficult to relate spin densities to actual stabilization energies, which might then be used in quantitative predictions of radical thermochemistry. Nonetheless, measurements of the extent of delocalization provide an interesting complementary measure of radical stability that can be used to explore the physical basis of the other radical stabilization energy schemes. Spin density distributions can be obtained by applying an appropriate electron localization scheme to the wavefunction generated by quantum-chemical calculations. Alternatively, one can use ESR-derived $\alpha$ - and $\beta$-proton hyperfine coupling constants, as these are proportional to spin densities for planar carbon-centred radicals. ${ }^{25}$ Of these, the $\beta$-proton hyperfine coupling constant is slightly less sensitive to deviations from planarity and therefore slightly more robust, although both measures give poor results for highly pyramidal radicals. ${ }^{24}$

In summary, several measures of relative radical stability have been proposed, each with their respective strengths and weaknesses. In the present work we compare some of the leading alternative schemes with a view to identifying their scope and limitations. To this end we present a new consistent database of $\mathrm{R}-\mathrm{H}, \mathrm{R}-\mathrm{Cl}, \mathrm{R}-\mathrm{CH}_{3}$ and $\mathrm{R}-\mathrm{R}$ BDEs, calculated using the high-level ab initio method G3(MP2)-RAD, and use these BDEs to calculate the radical stabilization energies for a wide range of primary, secondary and tertiary carbon-centred radicals. Values of the standard RSEs (i.e. as calculated by eqn (2)) are compared with the corresponding $\mathrm{RSE}_{\mathbf{Z}}$ values, $\mathrm{RSE}_{\mathrm{V}}$ values and the spin densities at the nominal radical carbon. The test set comprises the series of radicals $\mathrm{R}^{\bullet}$ such that $\mathrm{R}^{\bullet}={ }^{\cdot} \mathrm{CH}_{2} \mathrm{X},{ }^{\circ} \mathrm{CH}\left(\mathrm{CH}_{3}\right) \mathrm{X},{ }^{\bullet} \mathrm{C}\left(\mathrm{CH}_{3}\right)_{2} \mathrm{X}$ and $\mathrm{X}=\mathrm{H}$, $\mathrm{BH}_{2}, \mathrm{CH}_{3}, \mathrm{NH}_{2}, \mathrm{OH}, \mathrm{F}, \mathrm{SiH}_{3}, \mathrm{PH}_{2}, \mathrm{SH}, \mathrm{Cl}, \mathrm{Br}, \mathrm{N}\left(\mathrm{CH}_{3}\right)_{2}$, $\mathrm{NHCH}_{3}, \mathrm{NHCHO}, \mathrm{NHCOCH}_{3}, \mathrm{NO}_{2}, \mathrm{OCF}_{3}, \mathrm{OCH}_{2} \mathrm{CH}_{3}$, $\mathrm{OCH}_{3}, \mathrm{OCHO}, \mathrm{OCOCH}_{3}, \mathrm{Si}\left(\mathrm{CH}_{3}\right)_{3}, \mathrm{P}\left(\mathrm{CH}_{3}\right)_{2}, \mathrm{SC}\left(\mathrm{CH}_{3}\right)_{2} \mathrm{CN}$, $\mathrm{SCH}_{2} \mathrm{COOCH}_{3}, \mathrm{SCH}_{2} \mathrm{COOCH}_{3}, \mathrm{SCH}_{2} \mathrm{Ph}, \mathrm{SCH}_{3}, \mathrm{SO}_{2} \mathrm{CH}_{3}$, $\mathrm{S}(\mathrm{O}) \mathrm{CH}_{3}, \quad \mathrm{Ph}, \quad \mathrm{C}_{6} \mathrm{H}_{4}-p \mathrm{CN}, \quad \mathrm{C}_{6} \mathrm{H}_{4}-p \mathrm{NO}_{2}, \quad \mathrm{C}_{6} \mathrm{H}_{4}-p \mathrm{OCH}_{3}$, $\mathrm{C}_{6} \mathrm{H}_{4}-p \mathrm{OH}, \mathrm{CF}_{2} \mathrm{CF}_{3}, \mathrm{CF}_{2} \mathrm{H}, \mathrm{CF}_{3}, \mathrm{CCl}_{2} \mathrm{H}, \mathrm{CCl}_{3}, \mathrm{CH}_{2} \mathrm{Cl}$, $\mathrm{CH}_{2} \mathrm{~F}, \mathrm{CH}_{2} \mathrm{OH}, \mathrm{CH}_{2} \mathrm{Ph}$, cyclo- $\mathrm{CH}\left(\mathrm{CH}_{2}\right)_{2}, \mathrm{CH}_{2} \mathrm{CH}=\mathrm{CH}_{2}$, $\mathrm{CH}_{2} \mathrm{CH}_{3}, \quad \mathrm{CH}\left(\mathrm{CH}_{3}\right)_{2}, \quad \mathrm{C}\left(\mathrm{CH}_{3}\right)_{3}, \quad \mathrm{C} \equiv \mathrm{CH}, \quad \mathrm{CH}=\mathrm{CH}_{2}$, $\mathrm{CH}=\mathrm{CHCH}_{3}, \mathrm{CHO}, \mathrm{CN}, \mathrm{COCH}_{3}, \mathrm{CON}\left(\mathrm{CH}_{2} \mathrm{CH}_{3}\right)_{2}, \mathrm{CONH}_{2}$, $\mathrm{CONHCH}_{3}, \quad \mathrm{COOC}\left(\mathrm{CH}_{3}\right)_{3}, \quad \mathrm{COOCH}_{2} \mathrm{CH}_{3}, \quad \mathrm{COOCH}_{3}$, $\mathrm{COOH}, \mathrm{COPh} .{ }^{26}$ The test set was chosen to include several commonly encountered functional groups in synthesis or biology, cover a representative sample of electronic and steric properties, and include species for which one or other of the respective RSE schemes might be expected to break down.

\section{Computational procedures}

Standard $a b$ initio molecular orbital theory and density functional theory calculations were performed using Gaussian $03^{27}$ and Molpro 2006.6. ${ }^{28}$ Calculations were performed at a high level of theory chosen on the basis of previous assessment studies for radical stabilization energies and associated bond dissociation energies. ${ }^{29}$ Geometries were optimized at the B3-LYP/6-31G(d) level of theory, and frequencies were also calculated at this level and scaled by the recommended ${ }^{30}$ scale factors. For the radicals $\mathrm{R}^{\bullet}$, systematic conformational searching at a resolution of $120^{\circ}$ was carried out to ensure all conformations were global rather than merely local minimum energy structures. For the corresponding closed shell species, starting structures were created in which the $\mathrm{R}$ moiety was maintained in the same conformation as in the radical, and then the geometry was fully optimised to the nearest local minimum energy structure. In this way it was hoped to minimize contributions to the RSE from conformational changes between the openand closed-shell species. For the $\mathrm{R}-\mathrm{R}$ compounds, the $\mathrm{R}$ moieties were joined in a staggered conformation so as to minimize the contribution to the $\mathrm{R}-\mathrm{R}$ bond energy from interactions between the $\mathrm{X}$-substituents.

Improved energies were calculated at the G3(MP2)-RAD level of theory, a high-level composite ab initio molecular orbital theory method that approximates $\operatorname{CCSD}(\mathrm{T})$ calculations with a large triple zeta basis as the sum of the corresponding calculations with a double zeta basis set, and basis set corrections carried out at the $\mathrm{R}(\mathrm{O}) \mathrm{MP} 2$ level of theory. ${ }^{31}$ Formally, the method also contains a higher-level correction term, though this term cancels entirely from the RSE values calculated via the various schemes. G3(MP2)-RAD has been shown to reproduce a large test set of gas-phase experimental data to within chemical accuracy, ${ }^{31}$ and showed similar excellent performance in assessment studies for radical stabilization energies and related bond dissociation energies. ${ }^{29}$ For calculation of the global electrophilicity index, $\omega$, the vertical ionization potentials (IPs) and electron affinities (EAs) of all species were 
calculated at a much lower level of theory, B3-LYP/6-31G(d). These values were required as part of the $\mathrm{RSE}_{\mathrm{V}}$ calculations only and, since the $\mathrm{RSE}_{\mathrm{V}}$ model has been re-fitted to our BDE data, only the trends in the $\omega$ values are important in this instance. Our chosen level of theory is very similar to that adopted in the previous compilation of this scale,$^{19}$ and was selected on the basis of an initial benchmarking study for the set of all $\mathrm{CH}_{2} \mathrm{X}^{\bullet}$ radicals in which we established a very high correlation $(R=1.00$ and 0.99 respectively) between both the EAs and IPs at this level and the corresponding G3(MP2)-RAD benchmark values (details are provided in the ESI $\dagger$ ).

Enthalpies at $298 \mathrm{~K}$ were obtained from the geometries, frequencies and improved energies, by using the standard textbook formulae for the statistical thermodynamics of an ideal gas under harmonic oscillator/rigid rotor approximation, as implemented using our in-house T-Chem program, as described previously. ${ }^{32,33}$ Spin density distributions for each radical species were obtained using simple Mulliken population analyses, carried out in Gaussian using small basis set DFT calculations (in our case B3-LYP/6-31G(d)) as recommended. ${ }^{34}$ Previous work has shown that such Mulliken population analyses can adequately reproduce the spin density distributions, as calculated via more sophisticated methods such as Natural Bond Orbital analyses. ${ }^{34}$

\section{Results}

$\mathrm{R}-\mathrm{H}, \mathrm{R}-\mathrm{Cl}, \mathrm{R}-\mathrm{CH}_{3}$ and $\mathrm{R}-\mathrm{R}$ bond dissociation enthalpies (BDEs, $298.15 \mathrm{~K}$ ) were calculated for $\mathrm{R}={ }^{\circ} \mathrm{CH}_{2} \mathrm{X}$, - $\mathrm{CH}\left(\mathrm{CH}_{3}\right) \mathrm{X},{ }^{\circ} \mathrm{C}\left(\mathrm{CH}_{3}\right)_{2} \mathrm{X}$ and $\mathrm{X}=\mathrm{H}, \mathrm{BH}_{2}, \mathrm{CH}_{3}, \mathrm{NH}_{2}, \mathrm{OH}$, $\mathrm{F}, \mathrm{SiH}_{3}, \mathrm{PH}_{2}, \mathrm{SH}, \mathrm{Cl}, \mathrm{Br}, \mathrm{N}\left(\mathrm{CH}_{3}\right)_{2}, \mathrm{NHCH}_{3}, \mathrm{NHCHO}$, $\mathrm{NHCOCH}_{3}, \quad \mathrm{NO}_{2}, \quad \mathrm{OCF}_{3}, \quad \mathrm{OCH}_{2} \mathrm{CH}_{3}, \quad \mathrm{OCH}_{3}, \mathrm{OCHO}$, $\mathrm{OCOCH}_{3}, \mathrm{Si}\left(\mathrm{CH}_{3}\right)_{3}, \mathrm{P}\left(\mathrm{CH}_{3}\right)_{2}, \mathrm{SC}\left(\mathrm{CH}_{3}\right)_{2} \mathrm{CN}, \mathrm{SCH}_{2} \mathrm{COOCH}_{3}$, $\mathrm{SCH}_{2} \mathrm{COOCH}_{3}, \mathrm{SCH}_{2} \mathrm{Ph}, \mathrm{SCH}_{3}, \mathrm{SO}_{2} \mathrm{CH}_{3}, \mathrm{~S}(\mathrm{O}) \mathrm{CH}_{3}, \mathrm{Ph}$, $\mathrm{C}_{6} \mathrm{H}_{4}-p \mathrm{CN}, \quad \mathrm{C}_{6} \mathrm{H}_{4}-p \mathrm{NO}_{2}, \quad \mathrm{C}_{6} \mathrm{H}_{4}-p \mathrm{OCH}_{3}, \quad \mathrm{C}_{6} \mathrm{H}_{4}-p \mathrm{OH}$, $\mathrm{CF}_{2} \mathrm{CF}_{3}, \mathrm{CF}_{2} \mathrm{H}, \mathrm{CF}_{3}, \mathrm{CCl}_{2} \mathrm{H}, \mathrm{CCl}_{3}, \mathrm{CH}_{2} \mathrm{Cl}, \mathrm{CH}_{2} \mathrm{~F}, \mathrm{CH}_{2} \mathrm{OH}$, $\mathrm{CH}_{2} \mathrm{Ph}, \quad$ cyclo- $\mathrm{CH}\left(\mathrm{CH}_{2}\right)_{2}, \quad \mathrm{CH}_{2} \mathrm{CH}=\mathrm{CH}_{2}, \quad \mathrm{CH}_{2} \mathrm{CH}_{3}$, $\mathrm{CH}\left(\mathrm{CH}_{3}\right)_{2}, \mathrm{C}\left(\mathrm{CH}_{3}\right)_{3}, \mathrm{C} \equiv \mathrm{CH}, \mathrm{CH}=\mathrm{CH}_{2}, \mathrm{CH}=\mathrm{CHCH}_{3}$, $\mathrm{CHO}, \mathrm{CN}, \mathrm{COCH}_{3}, \mathrm{CON}\left(\mathrm{CH}_{2} \mathrm{CH}_{3}\right)_{2}, \mathrm{CONH}_{2}, \mathrm{CONHCH}_{3}$, $\mathrm{COOC}\left(\mathrm{CH}_{3}\right)_{3}, \mathrm{COOCH}_{2} \mathrm{CH}_{3}, \mathrm{COOCH}_{3}, \mathrm{COOH}$, and $\mathrm{COPh}$. BDEs are provided in Table 1; optimised geometries of all species are provided in the ESI. $\dagger$

Using the BDE data in Table 1, standard radical stabilization energies (RSEs) were calculated from the $\mathrm{R}-\mathrm{H}$ and $\mathrm{CH}_{3}-\mathrm{H}$ BDEs via eqn (2), and are provided in Table 2. Also included in this table are the spin densities on the nominal radical centre, and the corresponding $\mathrm{RSE}_{\mathrm{V}}$ and $\mathrm{RSE}_{\mathrm{Z}}$ values. The $\mathrm{RSE}_{Z}$ values were calculated from the $\mathrm{R}-\mathrm{Cl}$ and $\mathrm{R}-\mathrm{CH}_{3}$ BDEs via eqn (6) in conjunction with eqn (9) and (10). As described in the Introduction, eqn (9) and (10) are first satisfied simultaneously for values of the strain-free $\mathrm{R}-\mathrm{R}$ BDE and $\chi[\mathrm{R}]$. For this purpose, known values of $\chi[\mathrm{Cl}]=3.18$ and $\chi\left[\mathrm{CH}_{3}\right]=2.52$ were used in conjunction with the calculated $\mathrm{BDE}[\mathrm{R}-\mathrm{Cl}], \mathrm{BDE}\left[\mathrm{R}-\mathrm{CH}_{3}\right], \mathrm{BDE}[\mathrm{Cl}-\mathrm{Cl}]$ and $\mathrm{BDE}\left[\mathrm{CH}_{3}-\mathrm{CH}_{3}\right]$ values. The resulting $B D E[R-R]^{*}$ and $\chi[R]$ values were then substituted in eqn (6) along with the $\mathrm{BDE}\left[\mathrm{CH}_{3}-\mathrm{CH}_{3}\right]$ and $\chi\left[\mathrm{CH}_{3}\right]$ values. All of the resulting $\chi$ values are provided in
Table 3, along with the corresponding ionization potentials, electron affinities and corresponding values of the global electrophilicity index, $\omega$.

The $\mathrm{RSE}_{\mathrm{V}}$ values were first calculated by solving eqn (11) for $\operatorname{RSE}_{\mathrm{V}}\left[\mathrm{R}^{\bullet}\right]$ using known values of $\mathrm{BDE}[\mathrm{R}-\mathrm{Y}], \operatorname{RSE}_{\mathrm{V}}\left[\mathrm{Y}^{\bullet}\right], \chi\left[\mathrm{Y}^{\bullet}\right]$, $\chi\left[\mathrm{R}^{\bullet}\right], \omega\left[\mathrm{Y}^{\bullet}\right], \omega\left[\mathrm{R}^{\bullet}\right], a$ and $b$. This process was repeated for $\mathrm{Y}=\mathrm{H}, \mathrm{CH}_{3}, \mathrm{Cl}$, so as to obtain three 'independent' measures of the $\operatorname{RSE}_{\mathrm{V}}\left[\mathrm{R}^{\bullet}\right]$ for each $\mathrm{R}^{\bullet}$, along with an average value for each species. In performing the analysis, we made use of values of $\omega$ that were calculated using DFT calculations, as in ref. 19; values of $\chi$ were obtained by applying Pauling's equation to the $\mathrm{R}-\mathrm{Cl}$ and $\mathrm{R}-\mathrm{CH}_{3} \mathrm{BDE}$ data of the present work, as described above (see Table 3). As explained in the Introduction, the remaining parameters, $\operatorname{RSE}_{\mathrm{V}}\left[\mathrm{H}^{\bullet}\right]=235.8, \mathrm{RSE}_{\mathrm{v}}\left[\mathrm{CH}_{3}{ }^{*}\right]=190.6$, $\operatorname{RSE}_{\mathrm{V}}\left[\mathrm{Cl}^{\circ}\right]=145.2, a=-12.88 \mathrm{~kJ} \mathrm{~mol}^{-1} \mathrm{eV}^{-2}$ and $b=-216.50 \mathrm{~kJ} \mathrm{~mol}^{-1}$, have been obtained previously via fitting to a large initial test set of BDE data. ${ }^{19}$ Since these earlier data were calculated at a significantly lower level of theory than the present work, and using a very different test set, we also calculated a fifth set of $\mathrm{RSE}_{\mathrm{V}}$ estimates by re-fitting this scheme to our present set of high-level ab initio data. Thus, values of $\mathrm{RSE}_{\mathrm{V}}\left[\mathrm{R}^{\circ}\right]$ were obtained by fitting eqn (11) to the complete set of corresponding $\mathrm{R}-\mathrm{H}, \mathrm{R}-\mathrm{Cl}$ and $\mathrm{R}-\mathrm{CH}_{3} \mathrm{BDEs}$, yielding also the values for $\operatorname{RSE}_{\mathrm{V}}\left[\mathrm{H}^{\bullet}\right], \mathrm{RSE}_{\mathrm{V}}\left[\mathrm{CH}_{3}{ }^{\bullet}\right], \mathrm{RSE}_{\mathrm{V}}\left[\mathrm{Cl}^{\bullet}\right], a$ and $b$. Owing to practical limitations on the number of fit parameters we could handle, we fitted data for the primary, secondary and tertiary radicals separately; in each case a 69-parameter fit was performed on a set of 192 BDEs. The re-fitted RSE ${ }_{V}$ values for all radicals were selected for inclusion in Table 2 since they were most likely to be internally consistent with the other schemes; all five estimates of the $\mathrm{RSE}_{\mathrm{V}}$ value for each species are provided in Tables S4-S6 of the ESI $\dagger$ and will be compared with one another below.

\section{Discussion}

\section{Comparison of theory and experiment}

For a subset of the BDE data in Table 1, experimental data are available. These data, drawn largely from reference 35 are provided in Table $\mathrm{S} 1$ of the ESI $\dagger$, and are compared graphically with the corresponding theoretical data in Fig. 2. From this figure, it is seen that there is generally excellent agreement between the G3(MP2)-RAD values and the corresponding experimental data. Over the set of available values, the correlation coefficient between theory and experiment is 0.97 , and the mean absolute deviation of theory from experiment (MAD) is just $7.9 \mathrm{~kJ} \mathrm{~mol}^{-1}$. This compares very well with the scatter in the experimental data itself; for example, the MAD of alternative experimental values for the same system from one another is itself $5.6 \mathrm{~kJ} \mathrm{~mol}^{-1}$ and in some cases there are deviations of as much as $27 \mathrm{~kJ} \mathrm{~mol}^{-1}$. There are a small number of larger outliers, reflected in a maximum absolute deviation of theory from experiment of $39.6 \mathrm{~kJ} \mathrm{~mol}^{-1}$. However, on closer examination, it appears that most if not all of these outliers may be attributable to problems in the experimental data itself. For example, of the 5 individual experimental values with deviations from G3(MP2)-RAD that are greater than $30 \mathrm{~kJ} \mathrm{~mol}^{-1}$, two $\left(\mathrm{Cl}-\mathrm{CH}_{2} \mathrm{COOH}\right.$ and $\left.\mathrm{NH}_{2} \mathrm{CH}_{2}-\mathrm{CH}_{2} \mathrm{NH}_{2}\right)$ 
Table $1 \mathrm{R}-\mathrm{H}, \mathrm{R}-\mathrm{Cl}, \mathrm{R}-\mathrm{CH}_{3}$ and $\mathrm{R}-\mathrm{R}$ bond dissociation energies $\left(\Delta H_{298 \mathrm{~K}} \mathrm{BDE}\right.$ in $\left.\mathrm{kJ} \mathrm{mol}^{-1}\right)$ for $\mathrm{R}^{\bullet}={ }^{\bullet} \mathrm{CH}_{2} \mathrm{X}(\operatorname{primary}, \mathrm{P}),{ }^{\bullet} \mathrm{CH}(\mathrm{CH}) \mathrm{X}$ (secondary, $\mathrm{S}$ ) and $\bullet \mathrm{C}\left(\mathrm{CH}_{3}\right)_{2} \mathrm{X}$ (tertiary, $\left.\mathrm{T}\right)$ radicals $^{a}$

\begin{tabular}{|c|c|c|c|c|c|c|c|c|c|c|c|c|}
\hline \multirow[b]{2}{*}{$\mathrm{X}$} & \multicolumn{3}{|c|}{$\mathrm{BDE}[\mathrm{R}-\mathrm{H}]$} & \multicolumn{3}{|c|}{$\mathrm{BDE}[\mathrm{R}-\mathrm{Cl}]$} & \multicolumn{3}{|c|}{$\mathrm{BDE}\left[\mathrm{R}-\mathrm{CH}_{3}\right]$} & \multicolumn{3}{|c|}{$\mathrm{BDE}[\mathrm{R}-\mathrm{R}]$} \\
\hline & $\mathrm{P}$ & $\mathrm{S}$ & $\mathrm{T}$ & $\mathrm{P}$ & $\mathrm{S}$ & $\mathrm{T}$ & $\mathrm{P}$ & $\mathrm{S}$ & $\mathrm{T}$ & $\mathrm{P}$ & $\mathrm{S}$ & $\mathrm{T}$ \\
\hline $\mathrm{H}$ & 435.3 & 421.7 & 412.2 & 346.5 & 353.3 & 358.6 & 370.6 & 368.5 & 367.6 & 370.7 & 366.8 & 357.4 \\
\hline $\mathrm{BH}_{2}$ & 394.3 & 370.1 & 344.3 & 311.2 & 299.9 & 315.4 & 331.4 & 312.5 & 299.9 & 292.0 & 257.4 & 219.5 \\
\hline $\mathrm{CH}_{3}$ & 421.7 & 412.2 & 406.7 & 353.3 & 358.5 & 362.1 & 368.5 & 367.6 & 367.6 & 366.8 & 357.4 & 341.0 \\
\hline $\mathrm{NH}_{2}$ & 390.4 & 385.4 & 383.7 & 342.9 & 348.7 & 351.1 & 344.4 & 348.0 & 346.4 & 318.2 & 316.7 & 303.7 \\
\hline $\mathrm{OH}$ & 403.0 & 397.7 & 394.1 & 348.0 & 354.1 & 356.6 & 362.7 & 361.1 & 361.8 & 349.1 & 352.1 & 343.1 \\
\hline $\mathrm{F}$ & 422.5 & 415.6 & 411.7 & 353.5 & 358.2 & 360.7 & 384.6 & 382.8 & 381.0 & 383.5 & 386.0 & 377.6 \\
\hline $\mathrm{SiH}_{3}$ & 423.4 & 406.5 & 393.6 & 334.7 & 338.2 & 340.6 & 358.0 & 352.7 & 349.1 & 347.6 & 330.0 & 308.8 \\
\hline $\mathrm{PH}_{2}$ & 411.7 & 404.2 & 395.2 & 331.8 & 336.4 & 339.4 & 356.8 & 354.7 & 354.0 & 345.1 & 330.4 & 311.9 \\
\hline $\mathrm{SH}$ & 399.0 & 393.7 & 391.0 & 313.2 & 324.7 & 329.1 & 347.9 & 352.7 & 352.2 & 321.8 & 328.7 & 314.5 \\
\hline $\mathrm{Cl}$ & 415.0 & 408.5 & 404.6 & 331.3 & 336.7 & 339.6 & 370.7 & 370.1 & 369.0 & 365.6 & 364.3 & 352.5 \\
\hline $\mathrm{Br}$ & 419.9 & 412.3 & 407.4 & 332.8 & 337.3 & 339.5 & 373.4 & 371.8 & 369.9 & 373.5 & 368.1 & 352.5 \\
\hline $\mathrm{N}\left(\mathrm{CH}_{3}\right)_{2}$ & 389.2 & 380.6 & 385.7 & 343.5 & 350.5 & 353.4 & 333.9 & 338.0 & 338.6 & 291.3 & 283.0 & 251.2 \\
\hline $\mathrm{NHCH}_{3}$ & 388.6 & 385.0 & 384.3 & 320.6 & 350.9 & 353.5 & 343.6 & 343.7 & 341.7 & 313.1 & 290.7 & 275.0 \\
\hline $\mathrm{NHCHO}$ & 392.8 & 389.7 & 397.5 & 325.3 & 333.2 & 337.2 & 347.4 & 350.4 & 356.7 & 330.6 & 325.0 & 308.9 \\
\hline $\mathrm{NHCOCH}_{3}$ & 392.3 & 390.3 & 399.8 & 328.7 & 324.5 & 341.0 & 347.8 & 351.0 & 358.3 & 332.7 & 326.8 & 324.2 \\
\hline $\mathrm{NO}_{2}$ & 422.8 & 402.9 & 393.0 & 327.3 & 321.3 & 315.4 & 379.1 & 365.9 & 355.4 & 364.8 & 346.9 & 315.0 \\
\hline $\mathrm{OCF}_{3}$ & 422.6 & 414.6 & 414.2 & 343.7 & 337.8 & 341.7 & 383.8 & 377.7 & 371.0 & 379.4 & 353.7 & 356.1 \\
\hline $\mathrm{OCH}_{2} \mathrm{CH}_{3}$ & 403.7 & 398.7 & 398.7 & 334.9 & 347.9 & 360.6 & 363.8 & 358.3 & 358.5 & 350.7 & 326.4 & 338.3 \\
\hline $\mathrm{OCH}_{3}$ & 403.7 & 398.8 & 399.0 & 334.4 & 356.4 & 360.0 & 364.0 & 358.3 & 358.6 & 350.5 & 343.2 & 337.4 \\
\hline $\mathrm{OCHO}$ & 418.0 & 411.7 & 418.1 & 338.5 & 336.5 & 350.9 & 377.4 & 375.3 & 375.4 & 371.2 & 352.3 & 340.6 \\
\hline $\mathrm{OCOCH}_{3}$ & 416.8 & 410.9 & 417.7 & 340.4 & 351.7 & 352.5 & 376.0 & 374.7 & 374.4 & 371.2 & 372.8 & 340.8 \\
\hline $\mathrm{Si}\left(\mathrm{CH}_{3}\right)_{3}$ & 423.1 & 406.1 & 393.2 & 343.3 & 347.0 & 349.4 & 358.2 & 353.1 & 349.6 & 351.0 & 324.1 & 294.1 \\
\hline $\mathrm{P}\left(\mathrm{CH}_{3}\right)_{2}$ & 410.4 & 397.4 & 396.6 & 337.3 & 343.4 & 348.7 & 348.8 & 353.7 & 349.9 & 332.0 & 297.8 & 266.6 \\
\hline $\mathrm{SC}\left(\mathrm{CH}_{3}\right)_{2} \mathrm{CN}$ & 399.7 & 393.2 & 391.9 & 311.2 & 319.5 & 330.2 & 348.8 & 346.8 & 344.1 & 326.0 & 309.3 & 289.5 \\
\hline $\mathrm{SCH}_{2} \mathrm{COOCH}_{3}$ & 398.2 & 394.4 & 388.4 & 326.1 & 334.7 & 335.1 & 349.1 & 346.9 & 347.8 & 329.4 & 326.0 & 300.1 \\
\hline $\mathrm{SCH}_{2} \mathrm{Ph}$ & 396.7 & 391.5 & 395.3 & 313.6 & 325.5 & 333.6 & 346.1 & 350.6 & 351.1 & 323.0 & 313.0 & 312.2 \\
\hline $\mathrm{SCH}_{3}$ & 394.2 & 389.6 & 389.6 & 310.5 & 328.3 & 337.3 & 343.2 & 346.7 & 349.2 & 314.5 & 317.1 & 303.4 \\
\hline $\mathrm{SO}_{2} \mathrm{CH}_{3}$ & 437.7 & 421.1 & 408.1 & 335.6 & 346.8 & 343.8 & 389.3 & 378.4 & 370.0 & 403.4 & 361.7 & 298.9 \\
\hline $\mathrm{S}(\mathrm{O}) \mathrm{CH}_{3}$ & 426.8 & 388.6 & 381.3 & 325.4 & 325.0 & 327.4 & 354.8 & 345.6 & 341.6 & 344.2 & 310.9 & 282.7 \\
\hline $\mathrm{Ph}$ & 374.2 & 366.9 & 365.6 & 300.6 & 306.5 & 309.5 & 322.0 & 320.0 & 319.6 & 277.0 & 279.6 & 200.9 \\
\hline $\mathrm{C}_{6} \mathrm{H}_{4}-p \mathrm{CN}$ & 373.1 & 364.3 & 361.6 & 295.2 & 300.2 & 304.1 & 321.0 & 317.3 & 316.2 & 273.9 & 272.9 & 192.2 \\
\hline $\mathrm{C}_{6} \mathrm{H}_{4}-p \mathrm{NO}_{2}$ & 374.3 & 362.3 & 362.0 & 295.7 & 297.9 & 304.1 & 322.0 & 315.4 & 316.4 & 275.8 & 268.8 & 194.3 \\
\hline $\mathrm{C}_{6} \mathrm{H}_{4}-p \mathrm{OCH}_{3}$ & 372.0 & 365.4 & 364.5 & 300.8 & 306.9 & 312.1 & 319.9 & 318.2 & 319.1 & 272.2 & 277.0 & 200.1 \\
\hline $\mathrm{C}_{6} \mathrm{H}_{4}-p \mathrm{OH}$ & 372.1 & 365.8 & 365.2 & 300.5 & 306.6 & 311.6 & 320.2 & 319.2 & 319.7 & 273.1 & 277.4 & 200.7 \\
\hline $\mathrm{CF}_{2} \mathrm{CF}_{3}$ & 441.5 & 423.8 & 407.5 & 343.5 & 338.4 & 331.9 & 388.8 & 373.4 & 360.9 & 399.8 & 327.6 & 260.6 \\
\hline $\mathrm{CF}_{2} \mathrm{H}$ & 438.4 & 424.9 & 417.6 & 346.3 & 349.9 & 354.0 & 384.4 & 380.1 & 378.3 & 397.1 & 373.6 & 348.0 \\
\hline $\mathrm{CF}_{3}$ & 443.2 & 427.6 & 417.9 & 346.4 & 347.2 & 349.5 & 390.7 & 382.5 & 378.4 & 402.0 & 368.4 & 338.2 \\
\hline $\mathrm{CCl}_{2} \mathrm{H}$ & 430.7 & 415.9 & 405.1 & 344.2 & 349.7 & 345.4 & 379.4 & 372.1 & 363.6 & 386.8 & 366.4 & 291.6 \\
\hline $\mathrm{CCl}_{3}$ & 434.9 & 419.7 & 410.7 & 348.9 & 344.2 & 343.0 & 385.8 & 373.6 & 367.2 & 395.1 & 315.6 & 269.8 \\
\hline $\mathrm{CH}_{2} \mathrm{Cl}$ & 425.0 & 410.0 & 399.8 & 351.3 & 352.2 & 351.6 & 372.3 & 365.8 & 361.1 & 371.6 & 349.4 & 320.7 \\
\hline $\mathrm{CH}_{2} \mathrm{~F}$ & 429.5 & 418.7 & 411.8 & 351.7 & 355.6 & 358.2 & 375.1 & 374.7 & 372.7 & 377.3 & 364.1 & 348.8 \\
\hline $\mathrm{CH}_{2} \mathrm{OH}$ & 425.6 & 417.9 & 411.9 & 352.7 & 357.9 & 372.2 & 371.7 & 373.9 & 372.6 & 372.7 & 358.9 & 344.6 \\
\hline $\mathrm{CH}_{2} \mathrm{Ph}$ & 424.9 & 415.2 & 407.3 & 358.0 & 361.3 & 360.7 & 373.5 & 372.1 & 366.8 & 379.1 & 366.1 & 317.2 \\
\hline $\mathrm{CH}\left(\mathrm{CH}_{2}\right)_{2}$ & 411.8 & 406.1 & 403.7 & 344.5 & 349.9 & 356.7 & 360.0 & 362.9 & 358.5 & 350.4 & 301.2 & 271.0 \\
\hline $\mathrm{CH}_{2} \mathrm{CH}=\mathrm{CH}_{2}$ & 424.1 & 414.4 & 409.0 & 355.1 & 359.6 & 364.1 & 371.7 & 370.3 & 367.6 & 373.5 & 359.8 & 325.6 \\
\hline $\mathrm{CH}_{2} \mathrm{CH}_{3}$ & 423.1 & 415.8 & 409.4 & 355.1 & 360.2 & 366.0 & 370.3 & 368.9 & 367.7 & 370.2 & 357.0 & 321.1 \\
\hline $\mathrm{CH}\left(\mathrm{CH}_{3}\right)_{2}$ & 424.7 & 410.4 & 406.3 & 357.1 & 360.9 & 362.2 & 366.2 & 363.9 & 361.1 & 362.0 & 326.3 & 280.8 \\
\hline $\mathrm{C}\left(\mathrm{CH}_{3}\right)_{3}$ & 428.1 & 415.1 & 406.8 & 361.0 & 359.9 & 358.1 & 370.5 & 361.6 & 357.5 & 371.2 & 292.5 & 211.0 \\
\hline $\mathrm{CCH}$ & 382.4 & 371.3 & 363.3 & 291.3 & 296.9 & 300.0 & 326.9 & 324.6 & 322.5 & 281.7 & 279.7 & 268.0 \\
\hline $\mathrm{CH}=\mathrm{C}\left(\mathrm{CH}_{3}\right)_{2}$ & 358.0 & 348.8 & 357.4 & 287.4 & 282.8 & 300.3 & 304.0 & 303.9 & 298.2 & 239.8 & 212.0 & 144.4 \\
\hline $\mathrm{CH}=\mathrm{CH}_{2}$ & 363.3 & 350.7 & 346.6 & 287.5 & 289.8 & 294.6 & 308.6 & 305.6 & 305.0 & 245.4 & 223.4 & 183.8 \\
\hline $\mathrm{CH}=\mathrm{CHCH}_{3}$ & 361.4 & 351.8 & 348.0 & 289.4 & 291.7 & 296.8 & 307.3 & 306.7 & 306.0 & 245.3 & 225.8 & 185.7 \\
\hline $\mathrm{CHO}$ & 398.7 & 378.9 & 361.5 & 309.0 & 308.0 & 306.5 & 346.7 & 330.8 & 321.6 & 322.6 & 283.3 & 252.4 \\
\hline $\mathrm{CN}$ & 402.8 & 386.7 & 376.9 & 298.0 & 300.1 & 303.1 & 347.4 & 339.9 & 336.2 & 309.9 & 301.9 & 291.1 \\
\hline $\mathrm{COCH}_{3}$ & 402.8 & 381.3 & 370.9 & 314.8 & 312.3 & 315.8 & 351.1 & 331.6 & 327.4 & 333.2 & 288.3 & 260.9 \\
\hline $\mathrm{CON}\left(\mathrm{CH}_{2} \mathrm{CH}_{3}\right)_{2}$ & 412.6 & 395.1 & 396.0 & 321.2 & 319.9 & 328.2 & 360.1 & 347.3 & 332.5 & 358.0 & 300.8 & 259.3 \\
\hline $\mathrm{CON}\left(\mathrm{CH}_{3}\right)_{2}$ & 414.3 & 396.7 & 390.6 & 321.8 & 320.1 & 323.5 & 361.4 & 347.0 & 328.0 & 360.6 & 301.9 & 262.0 \\
\hline $\mathrm{CONH}_{2}$ & 411.8 & 393.1 & 384.4 & 335.7 & 330.3 & 333.2 & 359.4 & 346.3 & 340.3 & 352.1 & 318.5 & 296.2 \\
\hline $\mathrm{CONHCH}_{3}$ & 412.2 & 389.5 & 385.6 & 338.0 & 333.3 & 336.1 & 355.2 & 347.7 & 340.9 & 337.4 & 320.5 & 298.5 \\
\hline $\mathrm{COOC}\left(\mathrm{CH}_{3}\right)_{3}$ & 411.8 & 393.4 & 381.3 & 322.4 & 318.8 & 320.4 & 360.0 & 346.1 & 339.9 & 349.2 & 325.1 & 298.3 \\
\hline $\mathrm{COOCH}_{2} \mathrm{CH}_{3}$ & 411.9 & 393.2 & 380.5 & 320.3 & 316.0 & 317.6 & 359.9 & 345.4 & 338.7 & 348.2 & 320.0 & 294.0 \\
\hline $\mathrm{COOCH}_{3}$ & 412.0 & 393.3 & 380.6 & 319.8 & 314.9 & 316.7 & 360.0 & 345.3 & 338.6 & 347.9 & 318.2 & 292.7 \\
\hline $\mathrm{COOH}$ & 412.6 & 393.4 & 379.5 & 318.3 & 313.7 & 313.2 & 360.6 & 344.8 & 337.5 & 348.7 & 319.2 & 286.0 \\
\hline $\mathrm{COPh}$ & 404.8 & 385.2 & 376.5 & 315.5 & 306.8 & 311.1 & 353.0 & 335.5 & 318.2 & 340.3 & 282.3 & 247.5 \\
\hline
\end{tabular}

${ }^{a}$ All BDEs calculated at the G3(MP2)-RAD//B3-LYP/6-31G(d) level of theory (see text for further calculation details). 
Table 2 Standard $\operatorname{RSE}\left(\mathrm{kJ} \mathrm{mol}^{-1}\right), \mathrm{RSE}_{\mathrm{Z}}\left(\mathrm{kJ} \mathrm{mol}^{-1}\right), \mathrm{RSE}_{\mathrm{V}}$ refit $\left(\mathrm{kJ} \mathrm{mol}^{-1}\right)$ and Mulliken spin density $(\rho)$ on the nominal radical centre for $\cdot \mathrm{CH}_{2} \mathrm{X}$ (primary, $\left.\mathrm{P}\right),{ }^{\bullet} \mathrm{CH}\left(\mathrm{CH}_{3}\right) \mathrm{X}$ (secondary, $\left.\mathrm{S}\right)$ and ${ }^{\bullet} \mathrm{C}\left(\mathrm{CH}_{3}\right)_{2} \mathrm{X}$ (tertiary, T) radicals ${ }^{a}$

\begin{tabular}{|c|c|c|c|c|c|c|c|c|c|c|c|c|}
\hline \multirow[b]{2}{*}{$\mathrm{X}$} & \multicolumn{3}{|l|}{ RSE } & \multicolumn{3}{|l|}{$\mathrm{RSE}_{\mathbf{Z}}^{c}$} & \multicolumn{3}{|c|}{$\mathrm{RSE}_{\mathrm{V}}$ refit } & \multicolumn{3}{|l|}{$\rho$} \\
\hline & $\mathrm{P}$ & $\mathrm{S}$ & $\mathrm{T}$ & $\mathrm{P}$ & $\mathrm{S}$ & $\mathrm{T}$ & $\mathrm{P}$ & $\mathrm{S}$ & $\mathrm{T}$ & $\mathrm{P}$ & $\mathrm{S}$ & $\mathrm{T}$ \\
\hline$\overline{\mathrm{H}}$ & 0.0 & 13.5 & 23.0 & 0.0 & 2.6 & 4.4 & 185.7 & 179.9 & 176.4 & 1.16 & 1.09 & 1.02 \\
\hline $\mathrm{BH}_{2}$ & 40.9 & 65.2 & 91.0 & 39.3 & 58.9 & 80.1 & 147.3 & 125.8 & 110.8 & 0.90 & 0.81 & 0.73 \\
\hline $\mathrm{CH}_{3}$ & 13.5 & 23.0 & 28.5 & 2.6 & 4.4 & 5.1 & 180.9 & 176.8 & 174.9 & 1.09 & 1.02 & 0.96 \\
\hline $\mathrm{NH}_{2}$ & 44.9 & 49.9 & 51.5 & 29.3 & 26.3 & 29.3 & 157.9 & 155.7 & 153.9 & 0.89 & 0.86 & 0.83 \\
\hline $\mathrm{OH}$ & 32.3 & 37.6 & 41.1 & 8.5 & 11.3 & 10.9 & 172.6 & 167.8 & 166.8 & 0.93 & 0.89 & 0.85 \\
\hline $\mathrm{F}$ & 12.8 & 19.7 & 23.6 & -13.7 & -12.2 & -10.3 & 191.1 & 186.5 & 184.1 & 0.99 & 0.94 & 0.89 \\
\hline $\mathrm{SiH}_{3}$ & 11.8 & 28.8 & 41.7 & 12.6 & 18.5 & 23.0 & 173.6 & 164.4 & 157.8 & 1.05 & 0.99 & 0.93 \\
\hline $\mathrm{PH}_{2}$ & 23.5 & 31.1 & 40.0 & 13.8 & 16.1 & 17.1 & 168.5 & 164.6 & 161.2 & 0.98 & 0.94 & 0.90 \\
\hline $\mathrm{SH}$ & 36.2 & 41.6 & 44.3 & 23.4 & 18.0 & 18.4 & 157.2 & 158.7 & 157.8 & 0.94 & 0.91 & 0.87 \\
\hline $\mathrm{Cl}$ & 20.2 & 26.7 & 30.6 & 1.3 & 1.0 & 1.8 & 177.1 & 174.7 & 173.0 & 1.01 & 0.96 & 0.92 \\
\hline $\mathrm{Br}$ & 15.3 & 22.9 & 27.9 & -1.2 & -0.6 & 0.9 & 180.1 & 177.1 & 174.4 & 1.01 & 0.97 & 0.92 \\
\hline $\mathrm{N}\left(\mathrm{CH}_{3}\right)_{2}$ & 46.1 & 54.6 & 49.6 & 43.5 & 40.6 & 41.1 & 154.1 & 148.7 & 150.3 & 0.84 & 0.82 & 0.79 \\
\hline $\mathrm{NHCH}_{3}$ & 46.6 & 50.2 & 50.9 & 27.0 & 32.8 & 36.8 & 153.1 & 153.4 & 151.6 & 0.86 & 0.84 & 0.81 \\
\hline $\mathrm{NHCHO}$ & 42.5 & 45.5 & 37.8 & 23.2 & 20.5 & 14.0 & 156.5 & 157.0 & 163.2 & 0.90 & 0.86 & 0.82 \\
\hline $\mathrm{NHCOCH}_{3}$ & 43.0 & 44.9 & 35.4 & 23.0 & 19.6 & 12.6 & 157.1 & 156.6 & 165.3 & 0.91 & 0.87 & 0.82 \\
\hline $\mathrm{NO}_{2}$ & 12.4 & 32.3 & 42.2 & -3.9 & 7.3 & 16.7 & 184.3 & 169.1 & 159.1 & 0.95 & 0.85 & 0.77 \\
\hline $\mathrm{OCF}_{3}$ & 12.7 & 20.6 & 21.0 & -11.7 & -5.6 & -0.2 & 188.9 & 181.2 & 177.5 & 0.98 & 0.94 & 0.90 \\
\hline $\mathrm{OCH}_{2} \mathrm{CH}_{3}$ & 31.6 & 36.5 & 36.5 & 7.0 & 13.5 & 16.3 & 170.7 & 165.9 & 166.8 & 0.92 & 0.88 & 0.85 \\
\hline $\mathrm{OCH}_{3}$ & 31.5 & 36.5 & 36.3 & 6.8 & 15.3 & 15.9 & 170.8 & 166.8 & 166.9 & 0.92 & 0.88 & 0.85 \\
\hline $\mathrm{OCHO}$ & 17.2 & 23.6 & 17.2 & -5.5 & -3.4 & -4.8 & 183.2 & 178.7 & 182.1 & 0.98 & 0.93 & 0.90 \\
\hline $\mathrm{OCOCH}_{3}$ & 18.4 & 24.3 & 17.5 & -4.6 & -4.0 & -3.8 & 182.3 & 179.6 & 181.6 & 0.98 & 0.93 & 0.90 \\
\hline $\mathrm{Si}\left(\mathrm{CH}_{3}\right)_{3}$ & 12.2 & 29.1 & 42.0 & 13.0 & 19.5 & 24.4 & 174.9 & 165.4 & 158.9 & 1.04 & 0.98 & 0.93 \\
\hline $\mathrm{P}\left(\mathrm{CH}_{3}\right)_{2}$ & 24.9 & 37.8 & 38.6 & 22.7 & 18.0 & 23.8 & 164.8 & 162.5 & 160.1 & 0.91 & 0.90 & 0.87 \\
\hline $\mathrm{SC}\left(\mathrm{CH}_{3}\right)_{2} \mathrm{CN}$ & 35.6 & 42.0 & 43.3 & 22.9 & 23.8 & 27.2 & 157.1 & 154.8 & 153.5 & 0.90 & 0.88 & 0.85 \\
\hline $\mathrm{SCH}_{2} \mathrm{COOCH}_{3}$ & 37.0 & 40.8 & 46.9 & 21.5 & 24.6 & 23.5 & 159.1 & 156.7 & 154.9 & 0.92 & 0.89 & 0.86 \\
\hline $\mathrm{SCH}_{2} \mathrm{Ph}$ & 38.5 & 43.7 & 40.0 & 24.9 & 20.0 & 19.8 & 155.3 & 156.9 & 159.0 & 0.90 & 0.88 & 0.86 \\
\hline $\mathrm{SCH}_{3}$ & 41.0 & 45.6 & 45.6 & 27.8 & 24.1 & 22.3 & 152.5 & 154.3 & 156.3 & 0.90 & 0.88 & 0.85 \\
\hline $\mathrm{SO}_{2} \mathrm{CH}_{3}$ & -2.4 & 14.2 & 27.2 & -13.4 & -7.4 & 0.7 & 194.7 & 184.7 & 175.1 & 1.06 & 0.96 & 0.93 \\
\hline $\mathrm{S}(\mathrm{O}) \mathrm{CH}_{3}$ & 8.4 & 46.6 & 54.0 & 16.0 & 25.0 & 29.6 & 172.0 & 153.1 & 148.3 & 0.93 & 0.79 & 0.77 \\
\hline $\mathrm{Ph}$ & 61.0 & 68.3 & 69.7 & 48.7 & 51.3 & 52.2 & 134.4 & 129.5 & 128.8 & 0.79 & 0.77 & 0.75 \\
\hline $\mathrm{C}_{6} \mathrm{H}_{4}-p \mathrm{CN}$ & 62.1 & 71.0 & 73.6 & 49.6 & 53.6 & 55.3 & 133.0 & 126.6 & 125.0 & 0.75 & 0.73 & 0.71 \\
\hline $\mathrm{C}_{6} \mathrm{H}_{4}-p \mathrm{NO}_{2}$ & 61.0 & 73.0 & 73.2 & 48.6 & 55.5 & 55.1 & 134.1 & 124.7 & 125.3 & 0.75 & 0.71 & 0.68 \\
\hline $\mathrm{C}_{6} \mathrm{H}_{4}-p \mathrm{OCH}_{3}$ & 63.3 & 69.9 & 70.8 & 50.8 & 53.4 & 53.2 & 132.5 & 128.1 & 128.3 & 0.78 & 0.76 & 0.74 \\
\hline $\mathrm{C}_{6} \mathrm{H}_{4}-p \mathrm{OH}$ & 63.2 & 69.4 & 70.1 & 50.6 & 52.3 & 52.4 & 132.6 & 128.7 & 128.9 & 0.78 & 0.76 & 0.74 \\
\hline $\mathrm{CF}_{2} \mathrm{CF}_{3}$ & -6.2 & 11.5 & 27.8 & -15.5 & -2.1 & 9.8 & 197.3 & 182.0 & 168.6 & 1.07 & 1.00 & 0.94 \\
\hline $\mathrm{CF}_{2} \mathrm{H}$ & -3.1 & 10.3 & 17.6 & -12.6 & -9.3 & -7.7 & 193.9 & 187.2 & 184.0 & 1.09 & 1.02 & 0.95 \\
\hline $\mathrm{CF}_{3}$ & -8.0 & 7.7 & 17.3 & -17.7 & -11.1 & -7.6 & 199.4 & 189.2 & 183.7 & 1.08 & 1.01 & 0.94 \\
\hline $\mathrm{CCl}_{2} \mathrm{H}$ & 4.6 & 19.3 & 30.2 & -8.1 & -1.5 & 7.2 & 188.7 & 179.8 & 170.5 & 1.01 & 0.94 & 0.87 \\
\hline $\mathrm{CCl}_{3}$ & 0.4 & 15.5 & 24.5 & -14.2 & -2.8 & 3.4 & 194.6 & 181.3 & 174.3 & 1.01 & 0.94 & 0.88 \\
\hline $\mathrm{CH}_{2} \mathrm{Cl}$ & 10.2 & 25.2 & 35.5 & -1.6 & 5.5 & 10.9 & 185.0 & 174.5 & 167.9 & 1.00 & 0.92 & 0.85 \\
\hline $\mathrm{CH}_{2} \mathrm{~F}$ & 5.8 & 16.5 & 23.4 & -4.5 & -3.9 & -1.6 & 187.7 & 182.7 & 179.2 & 1.08 & 1.01 & 0.95 \\
\hline $\mathrm{CH}_{2} \mathrm{OH}$ & 9.6 & 17.4 & 23.3 & -0.9 & -2.9 & 1.4 & 184.3 & 182.2 & 180.4 & 1.07 & 1.02 & 0.95 \\
\hline $\mathrm{CH}_{2} \mathrm{Ph}$ & 10.4 & 20.1 & 27.9 & -2.4 & -0.4 & 5.8 & 185.4 & 180.6 & 174.4 & 1.08 & 1.02 & 0.95 \\
\hline $\mathrm{CH}\left(\mathrm{CH}_{2}\right)_{2}$ & 23.4 & 29.1 & 31.6 & 11.1 & 8.4 & 15.2 & 171.9 & 171.2 & 168.1 & 1.02 & 0.97 & 0.92 \\
\hline $\mathrm{CH}_{2} \mathrm{CH}=\mathrm{CH}_{2}$ & 11.1 & 20.9 & 26.3 & -0.8 & 1.4 & 5.6 & 183.7 & 179.1 & 175.7 & 1.09 & 1.03 & 0.96 \\
\hline $\mathrm{CH}_{2} \mathrm{CH}_{3}$ & 12.2 & 19.5 & 25.8 & 0.8 & 3.1 & 5.9 & 182.6 & 178.9 & 176.2 & 1.09 & 1.02 & 0.97 \\
\hline $\mathrm{CH}\left(\mathrm{CH}_{3}\right)_{2}$ & 10.6 & 24.8 & 29.0 & 5.8 & 9.4 & 13.4 & 181.3 & 174.3 & 170.9 & 1.09 & 1.03 & 0.97 \\
\hline $\mathrm{C}\left(\mathrm{CH}_{3}\right)_{3}$ & 7.1 & 20.1 & 28.4 & 1.4 & 12.0 & 16.9 & 185.3 & 174.5 & 168.7 & 1.09 & 1.03 & 0.97 \\
\hline $\mathrm{CCH}$ & 52.8 & 63.9 & 72.0 & 44.5 & 46.1 & 48.2 & 137.4 & 132.6 & 128.8 & 0.81 & 0.78 & 0.74 \\
\hline $\mathrm{CH}=\mathrm{C}\left(\mathrm{CH}_{3}\right)_{2}$ & 77.3 & 86.5 & 77.8 & 66.9 & 66.8 & 76.5 & 116.6 & 111.9 & 112.9 & 0.68 & 0.65 & 0.62 \\
\hline $\mathrm{CH}=\mathrm{CH}_{2}$ & 72.0 & 84.6 & 88.7 & 62.0 & 65.5 & 66.8 & 121.5 & 114.2 & 112.6 & 0.70 & $0.66^{b}$ & $0.64^{b}$ \\
\hline $\mathrm{CH}=\mathrm{CHCH}_{3}$ & 73.9 & 83.4 & 87.2 & 63.5 & 64.4 & 65.9 & 119.7 & 115.5 & 113.9 & 0.69 & 0.65 & $0.63^{b}$ \\
\hline $\mathrm{CHO}$ & 36.6 & 56.4 & 73.7 & 25.0 & 39.8 & 49.5 & 155.5 & 139.9 & 128.3 & 0.86 & 0.80 & 0.73 \\
\hline $\mathrm{CN}$ & 32.5 & 48.5 & 58.3 & 27.1 & 32.2 & 34.8 & 156.4 & 146.8 & 141.6 & 0.89 & 0.84 & 0.80 \\
\hline $\mathrm{COCH}_{3}$ & 32.4 & 53.9 & 64.4 & 20.4 & 39.2 & 44.2 & 160.6 & 141.6 & 135.6 & 0.91 & 0.84 & 0.78 \\
\hline $\mathrm{CON}\left(\mathrm{CH}_{2} \mathrm{CH}_{3}\right)_{2}$ & 22.6 & 40.1 & 39.3 & 11.8 & 23.4 & 40.5 & 169.9 & 155.8 & 148.0 & 0.98 & 0.91 & 0.87 \\
\hline $\mathrm{CON}\left(\mathrm{CH}_{3}\right)_{2}$ & 21.0 & 38.6 & 44.6 & 10.6 & 23.7 & 44.9 & 171.3 & 156.1 & 143.2 & 0.98 & 0.91 & 0.86 \\
\hline $\mathrm{CONH}_{2}$ & 23.4 & 42.2 & 50.8 & 11.2 & 24.7 & 32.1 & 170.8 & 155.6 & 149.1 & 0.98 & 0.91 & 0.86 \\
\hline $\mathrm{CONHCH}_{3}$ & 23.1 & 45.7 & 49.6 & 15.7 & 23.5 & 31.9 & 170.1 & 155.5 & 150.1 & 0.99 & 0.92 & 0.87 \\
\hline $\mathrm{COOC}\left(\mathrm{CH}_{3}\right)_{3}$ & 23.5 & 41.8 & 53.9 & 11.7 & 24.5 & 30.8 & 168.4 & 154.4 & 146.7 & 0.97 & 0.90 & 0.83 \\
\hline $\mathrm{COOCH}_{2} \mathrm{CH}_{3}$ & 23.4 & 42.0 & 54.7 & 12.2 & 25.4 & 31.9 & 168.4 & 153.6 & 145.5 & 0.97 & 0.90 & 0.83 \\
\hline $\mathrm{COOCH}_{3}$ & 23.2 & 41.9 & 54.6 & 12.2 & 25.6 & 32.1 & 168.6 & 153.5 & 145.4 & 0.97 & 0.89 & 0.83 \\
\hline $\mathrm{COOH}$ & 22.7 & 41.9 & 55.7 & 12.0 & 26.1 & 33.1 & 168.9 & 153.1 & 144.1 & 0.97 & 0.89 & 0.83 \\
\hline $\mathrm{COPh}$ & 30.4 & 50.0 & 58.8 & 18.6 & 35.2 & 54.2 & 162.7 & 144.5 & 131.7 & 0.90 & 0.82 & 0.76 \\
\hline
\end{tabular}

${ }^{a}$ All RSE values are based on the G3(MP2)-RAD//B3-LYP/6-31G(d) BDE data in Table 1. Mulliken spin densities were obtained at the B3-LYP/ 6-31G(d) level of theory. The RSE values were obtained by fitting eqn (11) to the calculated $\mathrm{R}-\mathrm{H}, \mathrm{R}-\mathrm{CH}_{3}$ and $\mathrm{R}-\mathrm{Cl} \mathrm{BDEs}$, yielding also the values for $\mathrm{RSE}_{\mathrm{V}}\left[\mathrm{H}^{\bullet}\right], \mathrm{RSE}_{\mathrm{V}}\left[\mathrm{CH}_{3}{ }^{\bullet}\right], \mathrm{RSE}_{\mathrm{V}}\left[\mathrm{Cl}^{\bullet}\right], a$ and $b$. Separate fits were performed for the primary, secondary and tertiary radicals. Alternative estimates of $\mathrm{RSE}_{\mathrm{V}}$, as obtained using the previously published ${ }^{19}$ values of $\mathrm{RSE}_{\mathrm{V}}\left[\mathrm{H}^{\bullet}\right], \mathrm{RSE}_{\mathrm{V}}\left[\mathrm{CH}_{3}{ }^{\bullet}\right], \mathrm{RSE}_{\mathrm{V}}\left[\mathrm{Cl}^{\bullet}\right], a$ and $b$, are provided in Tables $\mathrm{S}_{-}-\mathrm{S} 6$ of the $\mathrm{ESI} \dagger$ (see text for further calculation details). ${ }^{b}$ Maximum spin density is located on the $\pi$ carbon atom not the nominal radical centre. ${ }^{c} \mathrm{RSE}_{\mathrm{Z}} \mathrm{scheme}$ is applied by solving eqn (9) and (10) simultaneously, using known values of $\mathrm{BDE}[\mathrm{R}-\mathrm{Cl}], \mathrm{BDE}\left[\mathrm{R}-\mathrm{CH}_{3}\right], \chi[\mathrm{Cl}]$ and $\chi\left[\mathrm{CH}_{3}\right]$. 
Table 3 Electronegativity $(\chi)$, strain-free BDE[R-R $]^{*}$, global electrophilicity index $(\omega$ in eV), ionisation potential (IP in eV) and electron affinity (EA in eV) for ${ }^{\bullet} \mathrm{CH}_{2} \mathrm{X}$ (primary, $\left.\mathrm{P}\right),{ }^{\bullet} \mathrm{CH}\left(\mathrm{CH}_{3}\right) \mathrm{X}$ (secondary, $\mathrm{S}$ ) and ${ }^{\bullet} \mathrm{C}\left(\mathrm{CH}_{3}\right)_{2} \mathrm{X}$ (tertiary, T) radicals ${ }^{a}$

\begin{tabular}{|c|c|c|c|c|c|c|c|c|c|c|c|c|c|c|c|}
\hline \multirow[b]{2}{*}{$\mathrm{X}$} & \multicolumn{3}{|l|}{$\underline{\chi}$} & \multicolumn{3}{|c|}{$\underline{\mathrm{BDE}}[\mathrm{R}-\mathrm{R}]^{*}$} & \multicolumn{3}{|l|}{$\underline{\omega}$} & \multicolumn{3}{|l|}{ IP } & \multicolumn{3}{|l|}{ EA } \\
\hline & $\mathrm{P}$ & $\mathrm{S}$ & $\mathrm{T}$ & $\mathrm{P}$ & $\mathrm{S}$ & $\mathrm{T}$ & $\mathrm{P}$ & $\mathrm{S}$ & $\mathrm{T}$ & $\mathrm{P}$ & $\mathrm{S}$ & $\mathrm{T}$ & $\mathrm{P}$ & $\mathrm{S}$ & $\mathrm{T}$ \\
\hline $\mathrm{H}$ & 52 & 2.45 & 2.40 & 370.7 & 365.5 & 361.8 & 1.19 & 0.88 & 0.71 & 9.81 & 8.42 & 7.54 & -0.10 & -0.51 & -0.70 \\
\hline $\mathrm{BH}_{2}$ & 49 & 2.43 & 2.21 & 291.9 & 252.7 & 210.3 & 2.11 & 1.77 & 1.67 & 10.52 & .21 & 8.53 & 1.69 & 1.35 & 1.31 \\
\hline $\mathrm{CH}_{3}$ & 2.45 & 2.40 & 2.37 & 365.4 & 361.8 & 360.4 & 0.88 & 0.71 & 0.64 & 8.42 & 7.54 & 6.94 & -0.51 & -0.70 & -0.68 \\
\hline $\mathrm{NH}_{2}$ & 2.34 & 2.32 & 2.29 & 312.0 & 318.0 & 312.1 & 0.54 & 0.45 & 0.44 & 7.13 & 6.51 & 6.08 & -1.15 & -1.22 & -1.08 \\
\hline $\mathrm{OH}$ & 2.44 & 2.38 & 2.37 & 353.7 & 347.9 & 348.8 & 0.73 & 0.58 & 0.55 & 8.11 & 7.28 & 6.73 & -0.87 & -1.05 & -0.92 \\
\hline $\mathrm{F}$ & .57 & 2.52 & 2.49 & 398.0 & 395.1 & 391.3 & 1.05 & 0.83 & 0.74 & 9.44 & 8.35 & 7.61 & -0.36 & -0.64 & -0.63 \\
\hline $\mathrm{SiH}_{3}$ & 2.51 & 2.44 & 2.40 & 345.5 & 333.6 & 324.6 & 1.41 & 1.15 & 1.03 & 9.21 & 8.21 & 7.55 & 0.63 & 0.32 & 0.22 \\
\hline $\mathrm{PH}_{2}$ & 2.53 & 2.47 & 2.44 & 343.0 & 338.3 & 336.4 & 1.06 & 0.88 & 0.80 & 8.04 & 7.37 & 6.87 & 0.13 & -0.11 & -0.15 \\
\hline SH & 2.60 & 2.55 & 2.51 & 323.9 & 334.7 & 333.8 & 0.87 & 0.74 & 0.72 & 7.82 & 7.21 & 6.81 & -0.31 & -0.46 & -0.36 \\
\hline $\mathrm{Cl}$ & 2.64 & 2.59 & 2.56 & 368.1 & 368.5 & 367.0 & 1.12 & 0.95 & 0.87 & 8.99 & 8.17 & 7.59 & -0.01 & -0.19 & -0.21 \\
\hline $\mathrm{Br}$ & 2.65 & 2.60 & 2.57 & 372.9 & 371.8 & 368.7 & 1.19 & 1.03 & 0.95 & 8.83 & 8.10 & 7.56 & 0.22 & 0.04 & 0.00 \\
\hline $\mathrm{N}\left(\mathrm{CH}_{3}\right)_{2}$ & 2.25 & 2.23 & 2.21 & 283.6 & 289.3 & 288.4 & 0.58 & 0.48 & 0.45 & 6.34 & 5.88 & 5.55 & -0.66 & -0.81 & -0.77 \\
\hline $\mathrm{NHCH}_{3}$ & 2.51 & 2.27 & 2.23 & 316.6 & 305.1 & 297.1 & 0.55 & 0.46 & 0.45 & 6.66 & 6.16 & 5.78 & -0.89 & -1.01 & -0.89 \\
\hline $\mathrm{NHCHO}$ & 50 & 2.46 & 2.48 & 324.2 & 329.6 & 342.5 & 0.94 & 0.80 & 0.74 & 7.49 & 6.90 & 6.49 & 0.02 & & -0.21 \\
\hline $\mathrm{NHCOCH}_{3}$ & .48 & 2.54 & 2.46 & 324.7 & 331.4 & 345.4 & 0.86 & 0.73 & 0.68 & 7.17 & 6.63 & 6.26 & -0.09 & -0.27 & -0.29 \\
\hline $\mathrm{NO}_{2}$ & .74 & 2.68 & 2.64 & 378.4 & 356.1 & 337.1 & 2.59 & 2.24 & 2.00 & 11.36 & 9.81 & 8.92 & 2.33 & 2.01 & 1.78 \\
\hline $\mathrm{OCF}_{3}$ & 2.65 & 2.64 & 2.56 & 394.0 & 381.8 & 371.0 & 1.14 & 0.94 & 0.88 & 9.07 & 8.19 & 7.62 & 0.03 & -0.24 & -0.19 \\
\hline $\mathrm{OCH}_{2} \mathrm{CH}_{3}$ & 2.56 & 2.41 & 2.31 & 356.7 & 343.7 & 338.0 & 0.74 & 0.60 & 0.55 & 7.54 & 6.88 & 6.43 & -0.60 & -0.82 & -0.79 \\
\hline $\mathrm{OCH}_{3}$ & 2.56 & 2.34 & 2.32 & 357.1 & 340.0 & 338.8 & 0.75 & 0.61 & 0.56 & 7.68 & 6.99 & 6.52 & -0.61 & -0.83 & -0.78 \\
\hline $\mathrm{OCHO}$ & .64 & 2.63 & 2.52 & 381.6 & 377.4 & 380.1 & 1.17 & 0.99 & 0.93 & 8.59 & 7.79 & & 0.26 & 0.03 & 0.00 \\
\hline $\mathrm{OCOCH}_{3}$ & 2.61 & 2.51 & 2.50 & 379.9 & 378.7 & 378.1 & 1.06 & 0.88 & 0.84 & 8.22 & 7.48 & 7.22 & 0.08 & -0.15 & -0.18 \\
\hline $\mathrm{Si}(\mathrm{C}$ & 2.45 & 2.38 & 2.33 & 344.6 & 331.6 & 321.8 & 1.26 & 1.01 & 0.89 & 8.37 & 7.57 & 6.98 & 0.52 & 0.17 & 0.05 \\
\hline $\mathrm{P}\left(\mathrm{CH}_{3}\right)_{2}$ & 42 & 2.41 & 2.34 & 325.2 & 334.6 & 322.9 & 1.06 & 0.90 & 0.81 & 7.23 & 6.75 & 6.37 & 0.40 & 0.15 & 0.05 \\
\hline $\mathrm{SC}\left(\mathrm{CH}_{3}\right)_{2} \mathrm{CN}$ & 63 & 2.54 & 2.44 & 324.8 & 322.9 & 316.3 & 1.12 & 0.98 & 1.09 & 7.66 & 7.14 & 7.00 & 0.41 & 0.23 & 0.51 \\
\hline $\mathrm{SCH}_{2} \mathrm{COOCH}_{3}$ & 51 & 2.43 & 2.43 & 327.7 & 321.5 & 323.5 & 0.89 & 0.78 & 0.90 & 7.31 & 6.80 & 6 & -0.07 & -0.20 & 0.19 \\
\hline $\mathrm{SCH}_{2} \mathrm{Ph}$ & 2.59 & 2.53 & 2.47 & 320.8 & 330.6 & 331.1 & 0.89 & 0.78 & 0.81 & 7.02 & 6.56 & & 0.03 & -0.12 & 0.05 \\
\hline $\mathrm{SCH}_{3}$ & 2.59 & 2.47 & 2.42 & 315.0 & 322.4 & 326.0 & 0.83 & 0.72 & 0.71 & 7.29 & 6.78 & 6.47 & -0.23 & -0.36 & -0.28 \\
\hline $\mathrm{SO}_{2} \mathrm{CH}_{3}$ & 2.75 & 2.58 & 2.54 & 397.4 & 385.4 & 369.3 & 1.92 & 1.66 & 1.55 & 9.82 & 8.95 & 8.42 & 1.50 & 1.20 & 1.10 \\
\hline $\mathrm{S}(\mathrm{O}) \mathrm{CH}_{3}$ & 2.56 & 2.49 & 2.44 & 338.7 & 320.5 & 311.4 & 1.53 & 1.05 & 0.98 & 8.41 & 7.26 & 6. & 1.07 & 0.37 & 0.32 \\
\hline $\mathrm{Ph}$ & 50 & 2.43 & 2.41 & 273.2 & 268.0 & 266.3 & 1.21 & 1.10 & 1.03 & 7.02 & 6.63 & 6.33 & 0.77 & 0.64 & 0.57 \\
\hline $\mathrm{C}_{6} \mathrm{H}$ & 53 & 2.46 & 2.4 & 271.3 & 263.4 & 260.0 & 1.84 & 1.70 & 1.60 & 7.57 & 7.18 & 6.8 & 1.72 & 1.56 & 1.46 \\
\hline $\mathrm{C}_{6} \mathrm{H}_{4}-p \mathrm{NO}_{2}$ & 2.54 & 2.47 & 2.43 & 273.4 & 259.7 & 260.4 & 2.13 & 1.98 & 1.88 & 7.81 & 7.40 & 7.03 & 2.07 & 1.92 & 1.82 \\
\hline $\mathrm{C}_{6} \mathrm{H}_{4}-p \mathrm{OCH}_{3}$ & 2.48 & 2.42 & 2.38 & 269.0 & 263.9 & 264.1 & 1.02 & 0.94 & 0.88 & 6.42 & 6.12 & 5. & 0.52 & 0.42 & 0.36 \\
\hline $\mathrm{C}_{6} \mathrm{H}_{4}-p \mathrm{OH}$ & 2.48 & 2.43 & 2.39 & 269.5 & 266.1 & 265.8 & 1.04 & 0.95 & 0.90 & 6.56 & 6.23 & 5.98 & 0.53 & 0.42 & 0.38 \\
\hline $\mathrm{CF}_{2} \mathrm{CF}_{3}$ & 2.69 & 2.61 & 2.56 & 401.6 & 374.9 & 351.0 & 1.86 & 1.53 & 1.34 & 10.32 & 9.05 & 8.24 & 1.28 & 0.92 & 0.74 \\
\hline $\mathrm{CF}_{2} \mathrm{H}$ & .63 & 2.57 & 2.52 & 395.9 & 389.1 & 386.1 & 1.52 & 1.22 & 1.08 & 9.87 & 8.70 & 7.91 & 0.70 & 0.34 & 0.22 \\
\hline $\mathrm{CF}_{3}$ & .68 & 2.61 & 2.56 & 405.9 & & & 1.75 & 1.42 & 1.23 & 10.46 & 9.20 & 8.36 & 1.02 & 0.64 & 0.46 \\
\hline $\mathrm{CCl}_{2} \mathrm{H}$ & 61 & 2.5 & 2.47 & 6.8 & 373.6 & & 1.71 & 1.51 & 1. & & 8.55 & & 1.20 & 1.00 & 0.93 \\
\hline $\mathrm{CCl}_{3}$ & .62 & 2.56 & 2.52 & 399.0 & 376.3 & 363.8 & 1.89 & 1.70 & 1.53 & 9.55 & 8.79 & 8.07 & 1.49 & 1.31 & 1.14 \\
\hline $\mathrm{CH}_{2} \mathrm{Cl}$ & .49 & 2.44 & 2.40 & 373.8 & 359.7 & 348.9 & 1.55 & 1.36 & 1.28 & 9.18 & 8.32 & 7.74 & 0.94 & 0.76 & 0.72 \\
\hline $\mathrm{CH}_{2} \mathrm{~F}$ & 51 & 2.48 & 2.44 & 379.5 & 378.5 & 373.8 & 1.15 & 0.94 & 0.85 & 8.99 & 8.08 & 7.41 & 0.07 & -0.19 & -0.20 \\
\hline $\mathrm{CH}_{2} \mathrm{OH}$ & 8 & 2.46 & 2.33 & 372.5 & 376.5 & 36 & 0.98 & 0.82 & 0.77 & 8.43 & 7.61 & 7.04 & -0.22 & -0.39 & -0.30 \\
\hline $\mathrm{CH}_{2} \mathrm{Ph}$ & 45 & 2.41 & 2.38 & 375.4 & 371.4 & 9 & 0.98 & 0.84 & 0.80 & 7.8 & 7.25 & 6.68 & 0.00 & -0.19 & -0.10 \\
\hline $\mathrm{CH}\left(\mathrm{CH}_{2}\right)_{2}$ & 2.45 & 2.43 & 2.34 & 348.4 & 353.8 & 340.2 & 0.82 & 0.66 & 0.57 & 7.32 & 6.73 & 6.28 & -0.27 & -0.55 & -0.65 \\
\hline $\mathrm{CH}_{2} \mathrm{CH}=\mathrm{CH}_{2}$ & 2.46 & 2.41 & 2.36 & 372.2 & 367.7 & 359.3 & 1.00 & 0.82 & 0.74 & 8.19 & 7.46 & 6.90 & -0.07 & -0.32 & -0.34 \\
\hline $\mathrm{CH}_{2} \mathrm{CH}_{3}$ & 2.45 & 2.40 & 2.34 & 369.0 & 364.4 & 358.8 & 0.97 & 0.77 & 0.66 & 8.25 & 7.40 & 6.76 & -0.17 & -0.45 & -0.54 \\
\hline $\mathrm{CH}\left(\mathrm{CH}_{3}\right)_{2}$ & 2.40 & 2.35 & 2.32 & 359.0 & 351.7 & 343.9 & 0.96 & 0.76 & 0.64 & 8.10 & 7.31 & 6.73 & -0.13 & -0.44 & -0.59 \\
\hline $\mathrm{C}\left(\mathrm{CH}_{3}\right)_{3}$ & 2.40 & 2.34 & 2.32 & 367.9 & 346.6 & 336.9 & 0.95 & 0.76 & 0.65 & 7.99 & 7.24 & 6.66 & -0.13 & -0.41 & -0.55 \\
\hline $\mathrm{CCH}$ & 1 & 2. & 2.51 & 1.7 & 278.4 & 27 & 1.35 & 1.13 & $1 .($ & 8.50 & 7.74 & 7.21 & 0.68 & 0.41 & 0.32 \\
\hline $\mathrm{CH}=\mathrm{C}\left(\mathrm{CH}_{3}\right)_{2}$ & 2.46 & 2.49 & 2.31 & 236.8 & 237.0 & 217.5 & 0.94 & 0.80 & 0.7 & 6.93 & 6.46 & 6.20 & 0.20 & -0.01 & 0.00 \\
\hline $\mathrm{CH}=\mathrm{CH}_{2}$ & 2.50 & 2.45 & 2.41 & 246.5 & 239.6 & 237.0 & 1.14 & 0.97 & 0.94 & 7.95 & 7.30 & 6.93 & 0.37 & 0.15 & 0.20 \\
\hline $\mathrm{CH}=\mathrm{CHCH}_{3}$ & 2.47 & 2.45 & 2.40 & 243.5 & 241.8 & 238.8 & 0.97 & 0.81 & 0.80 & 7.30 & 6.75 & 6.46 & 0.15 & -0.09 & -0.01 \\
\hline $\mathrm{CHO}$ & 2.63 & 2.51 & 2.45 & 320.7 & 291.0 & 271.7 & 2.06 & 1.79 & 1.62 & 10.28 & 9.20 & 8.50 & 1.65 & 1.37 & 1.21 \\
\hline $\mathrm{CN}$ & 2.72 & 2.64 & 2.59 & 316.4 & & & & 1.66 & & 10.15 & 9.12 & & 1.51 & 1.17 & 0.98 \\
\hline $\mathrm{COC}$ & 2.62 & 2.48 & 2.42 & 329.9 & 292.3 & 282.2 & 1.89 & 1.63 & 1.49 & 9.81 & 8.81 & 8.16 & 1.43 & 1.17 & 1.04 \\
\hline $\mathrm{CON}\left(\mathrm{CH}_{2} \mathrm{CH}_{3}\right)_{2}$ & 2.64 & 2.55 & 2.36 & 347.0 & 323.9 & 289.6 & 1.62 & 1.38 & 1.19 & 8.63 & 7.84 & 7.33 & 1.18 & 0.90 & 0.65 \\
\hline $\mathrm{CON}\left(\mathrm{CH}_{3}\right)_{2}$ & 2.64 & 2.54 & 2.36 & 349.4 & 323.2 & 280.7 & 1.63 & 1.40 & 1.22 & 8.81 & 8.01 & 7.46 & 1.17 & 0.90 & 0.68 \\
\hline $\mathrm{CONH}_{2}$ & 2.52 & 2.46 & 2.38 & 348.2 & 321.2 & 306.4 & 1.73 & 1.45 & 1.31 & 9.52 & 8.49 & 7.87 & 1.20 & 0.90 & 0.76 \\
\hline $\mathrm{CONHCH}_{3}$ & 2.46 & 2.44 & 2.37 & 339.3 & 323.6 & 306.8 & 1.62 & 1.35 & 1.22 & 9.05 & 8.14 & 7.61 & 1.09 & 0.78 & 0.65 \\
\hline $\mathrm{COOC}\left(\mathrm{CH}_{3}\right)_{3}$ & 2.63 & 2.54 & 2.48 & 347.2 & 321.5 & 309.0 & 1.78 & 1.51 & 1.37 & 9.29 & 8.38 & 7.78 & 1.34 & 1.04 & 0.91 \\
\hline $\mathrm{COOCH}_{2} \mathrm{CH}_{3}$ & 2.64 & 2.56 & 2.50 & 346.3 & 319.8 & 306.7 & 1.81 & 1.53 & 1.39 & 9.48 & 8.52 & 7.89 & 1.35 & 1.05 & 0.92 \\
\hline $\mathrm{COOCH}_{3}$ & 2.65 & 2.57 & 2.50 & 346.2 & 319.4 & 306.4 & 1.83 & 1.55 & 1.40 & 9.64 & 8.62 & 7.97 & 1.37 & 1.06 & 0.93 \\
\hline & 5 & 2.5 & 2.5 & 346.6 & & & 1.95 & $1 .($ & 1.5 & 10.11 & 8.96 & 8.24 & 1.50 & 1.18 & 1.05 \\
\hline $\mathrm{COPh}$ & 2.63 & 2.56 & 2.38 & 333.3 & 300.1 & 262.2 & 2.01 & 1.80 & 1.62 & 8.94 & 8.22 & 7.81 & 1.79 & 1.57 & 1.35 \\
\hline
\end{tabular}

${ }^{a}$ The $\chi$ and strain-free R-R BDE values were obtained by fitting the RSE model to the G3(MP2)-RAD//B3-LYP/6-31G(d) bond energies in Table 1 . The principal values are obtained solving eqn (9) and (10) simultaneously, using known values of $\mathrm{BDE}[\mathrm{R}-\mathrm{Cl}], \mathrm{BDE}[\mathrm{R}-\mathrm{CH} 3], \chi[\mathrm{Cl}]$ and $\chi\left[\mathrm{CH}_{3}\right]$. The IP, EA and hence $\omega$ values are based on B3LYP/6-31G(d) calculations. See text for further details. 


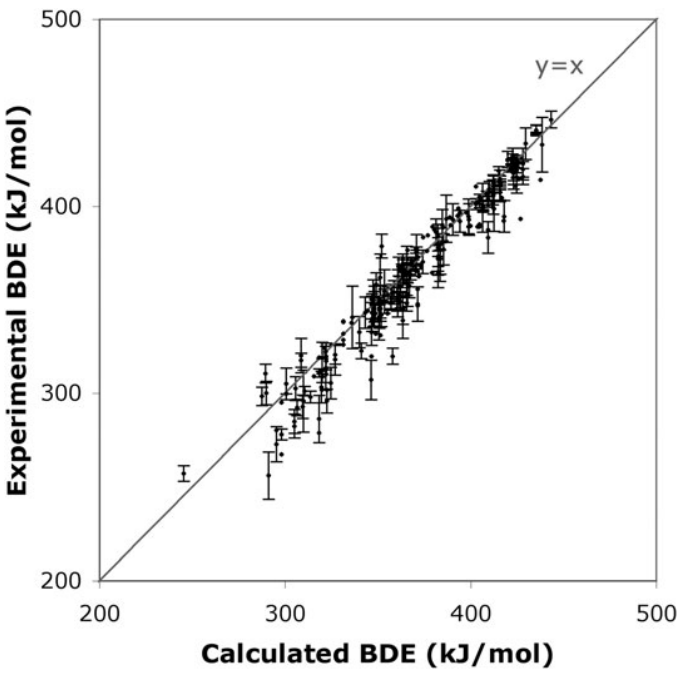

Fig. 2 Comparison of the G3(MP2)-RAD BDEs from Table 1 with available experimental data (data and sources provided in Table S1 of the $\mathrm{ESI} \dagger)$

had alternative experimental data available that were in

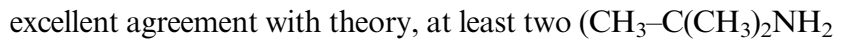
and $\mathrm{CN}\left(\mathrm{CH}_{3}\right)_{2} \mathrm{C}-\mathrm{C}\left(\mathrm{CH}_{3}\right)_{2} \mathrm{CN}$ ) were misquoted (in ref. 35) from their original references and (when corrected) were actually much closer to the theoretical data, and another $\left(\mathrm{H}-\mathrm{CH}_{2} \mathrm{SOCH}_{3}\right)$ was effectively a semi-empirical value estimated by fitting to acidities and oxidation potentials. A case-by-case analysis of the remaining smaller outliers $\left(<30 \mathrm{~kJ} \mathrm{~mol}^{-1}\right)$ is beyond the scope of this work, but it is clear from Fig. 2 that most theoretical values do fall within the scatter and/or quoted error bars of the experimental data. While it is certainly possible that some of the smaller outliers are due to genuine errors in the G3(MP2)-RAD calculations when handling specific problematic systems (such as molecules with low-lying excited states), it appears that in general G3(MP2)-RAD can calculate bond dissociation energies with a reliability that is at least comparable with experiment. Moreover, one would in any case expect improved performance for radical stabilisation energies, due to systematic error cancellation from the isodesmic reaction energies.

\section{Comparison of schemes}

To explore the physical basis of the alternative radical stability schemes, we first examined the correlation between the radical stabilization energy (as calculated using the various schemes) and the spin density on the nominal radical centre. As explained in the Introduction, one might reasonably expect that radical stability should increase with the extent of delocalisation of the unpaired electron, at least within a class of related radicals. Since the spin density distribution is measured for individual radical species, independent of any closed shell reference compounds, it provides an attractive means for testing whether the bond strengths of the reference compounds in the various schemes are contributing to the measured radical stabilization energies. Fig. 3 shows the RSEs calculated by the various schemes as a function of spin density. In each case, the test set of primary $\left({ }^{\circ} \mathrm{CH}_{2} \mathrm{X}\right)$, secondary $\left({ }^{\bullet} \mathrm{CH}\left(\mathrm{CH}_{3}\right) \mathrm{X}\right)$ and tertiary $\left({ }^{\bullet} \mathrm{C}\left(\mathrm{CH}_{3}\right)_{3}\right)$ radicals are labelled separately; however, the correlation coefficient refers to the test set as a whole. Fig. 4 shows the stabilization energies from the $\mathrm{RSE}_{\mathrm{Z}}$ and $\mathrm{RSE}_{\mathrm{V}}$ schemes, plotted as a function of the corresponding standard RSEs.

Fig. 3a shows that there is good correlation between the standard RSE and the spin density for each of the three classes

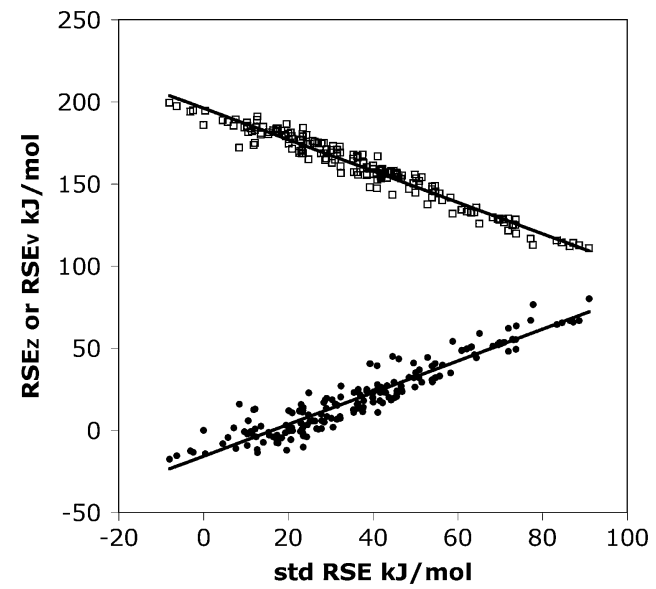

Fig. 4 Correlation between standard $\mathrm{RSE}$ and $\operatorname{RSE}_{\mathrm{Z}}(\bullet, R=0.95)$ and $\operatorname{RSE}_{\mathrm{V}}(\square, R=-0.98)$.
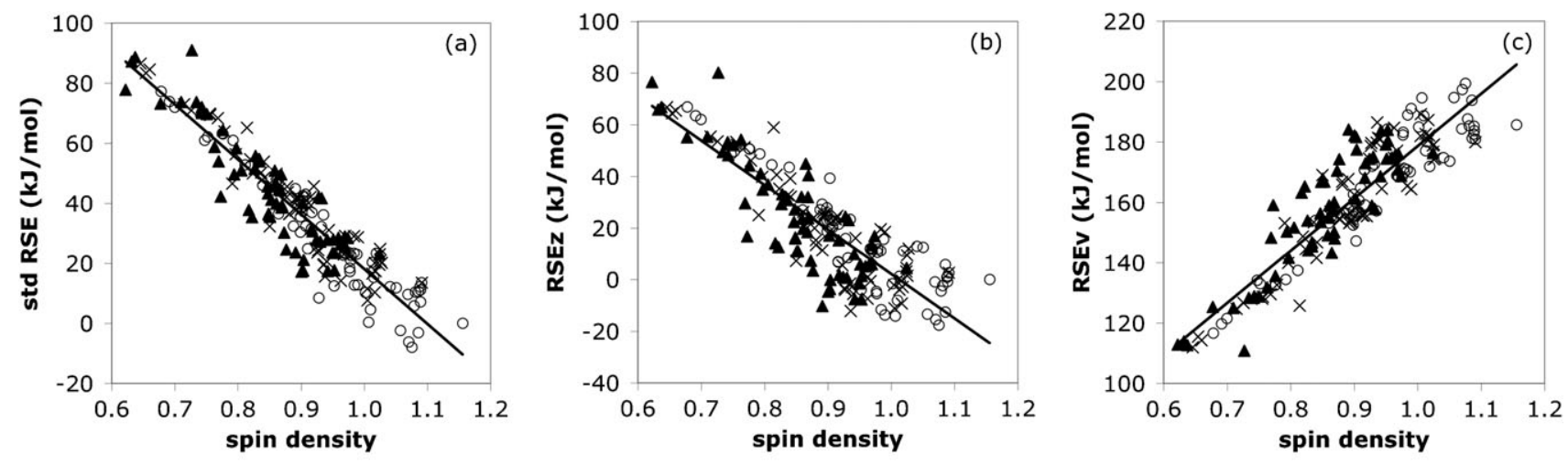

- Primary $\times$ Secondary $\Delta$ Tertiary Overall -

Fig. 3 Correlation between spin density on the nominal radical carbon and stabilization energy, as calculated under the various schemes: (a) the standard $\operatorname{RSE}(R=-0.94)$; (b) $\operatorname{RSE}_{\mathrm{Z}}(R=-0.86)$; (c) $\operatorname{RSE}_{\mathrm{V}}(R=0.90)$. 
of radical $(R=-0.94,-0.94,-0.90$ for primary, secondary and tertiary respectively) and overall $(R=-0.93)$. The correlation is poorest for the tertiary radicals, possibly due to increased steric and polar effects in this set. It should also be noted that the largest outlier occurs for the ${ }^{\circ} \mathrm{C}\left(\mathrm{CH}_{3}\right)_{2} \mathrm{BH}_{2}$ radical, where the stabilization energy is greater than might be expected on the basis of its extent of delocalisation. This may be due to $\sigma$ donation by the $\mathrm{BH}_{2}$ group, which can stabilize the electron deficient radical centre without delocalising the unpaired electron - in such cases, the use of spin densities alone would lead one to underestimate relative radical stability. For the same reason, one might expect that the use of spin densities might lead one to overestimate radical stability for radicals bearing $\sigma$-withdrawing groups. These are probably less obvious as outliers in the present test set because there are a much greater number of them built into the correlation. Nonetheless, despite these exceptions, the generally good correlation between these two independent measures of relative radical stability confirms that both can provide a reasonable semi-quantitative, if not quantitative, guide to relative radical stability in simple carbon-centred radicals.

Examining Fig. 4, we note that both the $\mathrm{RSE}_{\mathrm{Z}}$ and $\mathrm{RSE}_{\mathrm{V}}$ schemes are in good correlation with the standard RSEs. The $\mathrm{RSE}_{\mathrm{Z}}$ scheme has a positive correlation coefficient of 0.95 ; the $\mathrm{RSE}_{\mathrm{V}}$ scheme has a negative value of -0.98 , due to an opposite sign convention. Not surprisingly then, both schemes also correlate well with the spin densities, having correlation coefficients of -0.86 and 0.90 respectively. As in the case of the standard RSEs, the correlation with spin densities becomes progressively worse as $\mathrm{R}$ becomes more hindered, reflecting the increasing difficulty of quantitatively accounting for steric and/or polar effects in the closed-shell reference species. It should also be noted that the overall correlations of $\mathrm{RSE}_{Z}$ and $\mathrm{RSE}_{\mathrm{V}}$ with spin density are slightly worse than for the standard RSEs, suggesting that for simple carbon-centred radicals the standard scheme may be superior. At the same time, the consistent predictions of all three schemes do provide strong encouragement that both the $\mathrm{RSE}_{\mathrm{V}}$ and $\mathrm{RSE}_{\mathrm{Z}}$ schemes are correcting adequately for the bond energies in their closedshell reference compounds, implying that they may be suitable for cases (such as non-carbon-centred radicals) where the standard scheme is expected to breakdown.

To probe the validity of these bond energy corrections further, we first examined the internal consistency of the $\mathrm{RSE}_{\mathrm{V}}$ scheme. As noted in the Results section, 5 different estimates of $\mathrm{RSE}_{\mathrm{V}}$ were actually calculated. Those in Table 2 were obtained by re-fitting the $\mathrm{RSE}_{\mathrm{V}}$ scheme to the current set of $\mathrm{R}-\mathrm{H}, \mathrm{R}-\mathrm{Cl}$ and $\mathrm{R}-\mathrm{CH}_{3} \mathrm{BDE}$ data. However, a further 4 values were obtained by using the literature values ${ }^{19}$ of $\operatorname{RSE}_{\mathrm{V}}\left[\mathrm{H}^{\bullet}\right], \mathrm{RSE}_{\mathrm{V}}\left[\mathrm{CH}_{3}{ }^{\bullet}\right], \mathrm{RSE}_{\mathrm{V}}\left[\mathrm{Cl} l^{\bullet}\right], a$ and $b$ in conjunction with either the $\mathrm{R}-\mathrm{H}, \mathrm{R}-\mathrm{CH}_{3}, \mathrm{R}-\mathrm{Cl} \mathrm{BDEs}$ or their average. The $\mathrm{RSE}_{\mathrm{V}}$ data plotted in Fig. 3 and 4 are based on the re-fitted parameters, as these were expected to have the greatest internal consistency with the other data in our study. Comparing these results with the alternative $\mathrm{RSE}_{\mathrm{V}}$ estimates (see Tables S4-S6 of the ESI $\dagger$ ) we note that the $\mathrm{RSE}_{\mathrm{V}}$ scheme is not, as we expected, insensitive to the choice of the bond energy used to implement (or parameterise) it. In all cases, the 5 alternative $\mathrm{RSE}_{\mathrm{V}}$ values have mean absolute deviations from one another ranging from $0.8 \mathrm{~kJ} \mathrm{~mol}^{-1}$ to $18 \mathrm{~kJ} \mathrm{~mol}^{-1}$, with maximum absolute deviations ranging from $2.2 \mathrm{~kJ} \mathrm{~mol}^{-1}$ to over $32 \mathrm{~kJ} \mathrm{~mol}^{-1}$. The $\mathrm{RSE}_{\mathrm{V}}$ values derived from $\mathrm{R}-\mathrm{Cl}$ BDEs show the largest deviations from the other data, and also show the worst correlation with the corresponding spin densities $(R \approx 0.85)$, implying that the bond energy corrections are less reliable for the $\mathrm{C}-\mathrm{Cl}$ bonds. Interestingly, the highest correlation with spin density, yielding results comparable to the standard RSE scheme, occurs when the $\mathrm{RSE}_{\mathrm{V}}$ scheme uses the R-H BDEs (i.e. those on which the standard RSE scheme is also based), and we recommend therefore that $\mathrm{R}-\mathrm{H}$ BDEs be used for the implementation of the $\mathrm{RSE}_{\mathrm{V}}$ scheme for carbon-centred radicals.

To examine further the physical basis of the $\mathrm{RSE}_{\mathrm{Z}}$ scheme, the differences between the calculated R-R BDE and the estimated strain free $\mathrm{R}-\mathrm{R}$ BDE for each primary, secondary and tertiary R-group in the test set are plotted in Fig. 5. From this graph, we see that the differences are large and positive for the set of tertiary radicals, smaller for the secondary radicals and in most cases negligible for the primary radicals. This reflects the increasing effect of steric interactions on the $\mathrm{R}-\mathrm{R}$ bond as $\mathrm{R}$ becomes more hindered. Pleasingly, these corrections are largest when the non-methyl substituents are also bulky groups such as $\mathrm{C}\left(\mathrm{CH}_{3}\right)_{3}$.

For the primary radicals, one would expect minimal steric effects in $\mathrm{R}-\mathrm{R}$, and indeed there is generally good agreement between the calculated $\mathrm{R}-\mathrm{R} \mathrm{BDE}$ and the estimated strain free $\mathrm{R}-\mathrm{R}$ BDE. The only significant "outliers" are $\mathrm{X}=\mathrm{F}, \mathrm{NO}_{2}$, $\mathrm{OCF}_{3}, \mathrm{CON}\left(\mathrm{CH}_{2} \mathrm{CH}_{3}\right)_{2}$ and $\mathrm{CON}\left(\mathrm{CH}_{3}\right)_{2}$, each having strainfree $\mathrm{R}-\mathrm{R}$ BDEs with deviations of between 10 and $15 \mathrm{~kJ} \mathrm{~mol}^{-1}$ from the corresponding G3(MP2)-RAD values. In applying the RSE scheme, we solved eqn (9) and (10) simultaneously, implicitly assuming that the G3(MP2)-RAD calculations and Pauling's equation are in perfect agreement for the $\mathrm{R}-\mathrm{Cl}$ and $\mathrm{R}-\mathrm{CH}_{3} \mathrm{BDEs}$. In this way, any deviations in these values due, for example, to the uncertainty in the ab initio calculations (approximately $5 \mathrm{~kJ} \mathrm{~mol}^{-1}$ ) are compensated for by incorrect values of the $\Delta \chi$ term and the resulting strain free $\mathrm{R}-\mathrm{R}$ BDE. The reliability of the calculated $\chi\left[\mathrm{CH}_{2} \mathrm{X}\right]$ increases as the $\Delta \chi^{2}$ term becomes larger. $\Delta \chi^{2}$ is small in eqn (9), but considerably larger in eqn (10). If we use eqn (10) with the known $\chi[\mathrm{Cl}]=3.18$ and the G3(MP2)-RAD values of $\mathrm{BDE}[\mathrm{Cl}-\mathrm{Cl}]$ and $\mathrm{BDE}\left[\mathrm{XCH}_{2}-\mathrm{CH}_{2} \mathrm{X}\right]$, more reliable values of $\chi\left[\mathrm{CH}_{2} \mathrm{X}\right]$ can be afforded. Values so obtained were thus used to calculate $\mathrm{BDE}\left[\mathrm{CH}_{3}-\mathrm{CH}_{2} \mathrm{X}\right]$ by eqn (10), with the known $\chi\left[\mathrm{CH}_{3}\right]=2.52$ and the G3(MP2)-RAD values of $\mathrm{BDE}\left[\mathrm{CH}_{3}-\mathrm{CH}_{3}\right]$ and $\mathrm{BDE}\left[\mathrm{XCH}_{2}-\mathrm{CH}_{2} \mathrm{X}\right]$, and the results are in good agreement with their corresponding G3(MP2)-RAD values. When this is done, most $\chi\left[\mathrm{CH}_{2} \mathrm{X}\right]$ values change negligibly but there is marked improvement for the larger outliers, to the extent that all $\mathrm{BDE}\left[\mathrm{CH}_{3}-\mathrm{CH}_{2} \mathrm{X}\right]$ values are now matched by Pauling's equation to within an MAD of $2.18 \mathrm{~kJ} \mathrm{~mol}^{-1}$ with a maximum absolute deviation of just $9.3 \mathrm{~kJ} \mathrm{~mol}^{-1}$, a testament to the remarkable performance and consistency of both Pauling's equation and the G3(MP2)-RAD calculations. Full details of this alternative approach for all primary species of Table 1 are provided in Table S2 of the ESI. $\dagger$ Because the good agreement so obtained indicates that steric effects are absent or minimal with the primary radicals, it is also worth noting that 


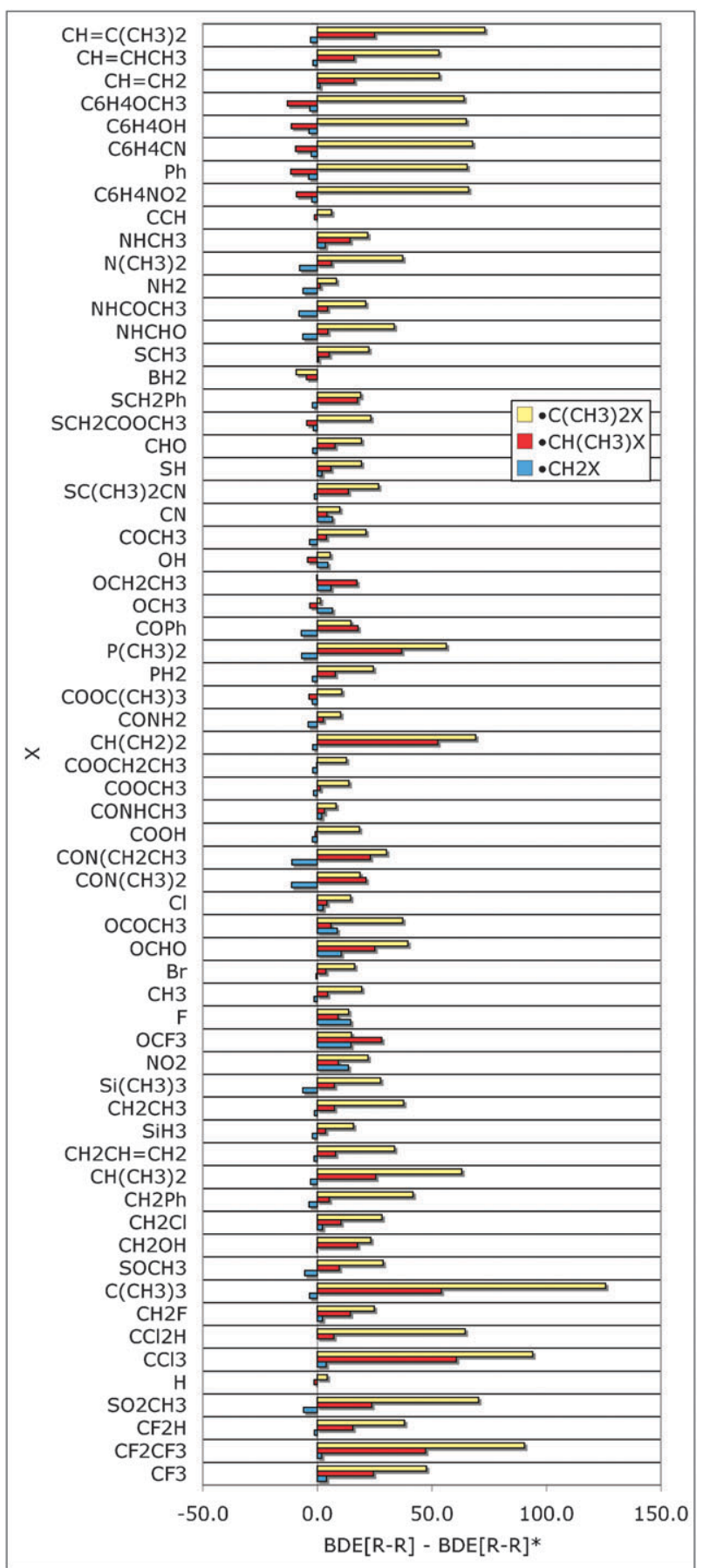

Fig. 5 Difference between the actual $B D E[R-R]$, as obtained from the G3(MP2)-RAD calculations, and the strain-free BDE[R-R $]^{*}$, as obtained by applying the $\mathrm{RSE}_{\mathrm{Z}}$ model to the G3(MP2)-RAD R-CH and $\mathrm{R}-\mathrm{Cl} \mathrm{BDE}$ data.

$\mathrm{BDE}\left[\mathrm{XCH}_{2}-\mathrm{CH}_{2} \mathrm{X}^{\prime}\right]$ for any combination of the 64 entries of Table 1 can be reliably estimated by $\mathrm{BDE}\left[\mathrm{XCH}_{2}-\mathrm{CH}_{2} \mathrm{X}^{\prime}\right]=$ $\frac{1}{2}\left(\mathrm{BDE}\left[\mathrm{XCH}_{2}-\mathrm{CH}_{2} \mathrm{X}\right]+\mathrm{BDE}\left[\mathrm{X}^{\prime} \mathrm{CH}_{2}-\mathrm{CH}_{2} \mathrm{X}^{\prime}\right]+96\left(\chi\left[\mathrm{CH}_{2} \mathrm{X}\right]-\right.\right.$ $\left.\chi\left[\mathrm{CH}_{2} \mathrm{X}^{\prime}\right]\right)^{2}\left[\mathrm{~kJ} \mathrm{~mol}^{-1}\right]$.

Application of the $\mathrm{RSE}_{Z}$ scheme also yields values of the electronegativity parameters $\chi$, and these too follow chemically intuitive trends. For example, the two lowest electronegativity values of $\chi\left[{ }^{\bullet} \mathrm{CH}_{2} \mathrm{X}\right]$ in Table 3 are $\chi\left[{ }^{\bullet} \mathrm{CH}_{2} \mathrm{~N}\left(\mathrm{CH}_{3}\right)_{2}\right]=2.25$ and $\chi\left[{ }^{\bullet} \mathrm{CH}_{2} \mathrm{NH}_{2}\right]=2.34$. As might be expected, the powerfully electron donating groups $\mathrm{N}\left(\mathrm{CH}_{3}\right)_{2}$ and $\mathrm{NH}_{2}$ decrease the electron attracting tendency of carbon. The three highest $\chi\left[{ }^{\bullet} \mathrm{CH}_{2} \mathrm{X}\right]$ are $\chi\left[{ }^{\bullet} \mathrm{CH}_{2} \mathrm{SO}_{2} \mathrm{CH}_{3}\right]=2.75, \chi\left[{ }^{\bullet} \mathrm{CH}_{2} \mathrm{NO}_{2}\right]=2.74$ and $\chi\left[{ }^{\bullet} \mathrm{CH}_{2} \mathrm{CN}\right]=2.72$, where the powerfully electron withdrawing groups $\mathrm{SO}_{2} \mathrm{CH}_{3}, \mathrm{NO}_{2}$ and $\mathrm{CN}$ increase that tendency. Thus, the $\mathrm{RSE}_{Z}$ scheme does appear to yield chemically intuitive values of the electronegativity parameter and the strain free $\mathrm{R}-\mathrm{R}$ BDE. This, together with the good overall correlation of the $\mathrm{RSE}_{Z}$ values with the spin densities, provides confidence that the bond energy corrections in this scheme are physically realistic, and might therefore be used also for non-carbon-centred radicals. It is also worth emphasizing that, in contrast to many other bond energy schemes, this excellent performance is attained without recourse to global numerical fittings, and depends only on the application of Pauling's equation to a single pair of known bond dissociation energies.

\section{Structure-reactivity trends}

Having compiled one of the largest RSE data sets to date for simple carbon-centred radicals, we can now comment on the effects of substituents on the data. Fig. 6 shows the standard RSE values for the primary ${ }^{\bullet} \mathrm{CH}_{2} \mathrm{X}$, secondary ${ }^{\bullet} \mathrm{CH}\left(\mathrm{CH}_{3}\right) \mathrm{X}$ and tertiary ${ }^{\bullet} \mathrm{C}\left(\mathrm{CH}_{3}\right)_{2} \mathrm{X}$ radicals, respectively. In all three cases, the data are plotted in the same order, based on increasing radical stability of the primary radicals, ${ }^{\bullet} \mathrm{CH}_{2} \mathrm{X}$, as measured via the standard RSEs. Many previous works have discussed the effects of substituents on the stability of carbon centred radicals, ${ }^{5,36}$ and the results herein are consistent with these earlier findings. In particular, it is seen that the most stabilized radicals are those including strong $\pi$-accepting $\alpha$ substituents such as the phenyl and allylic derivatives; weaker stabilizers such as cyano and various types of carbonyl groups have their stabilization effect somewhat diminished by concurrent $\sigma$ withdrawal effects; groups, such as alkyl, that stabilize by hyperconjugation only are among the weakest stabilizers. Lone pair donor groups are also strong radical stabilizers, with the stabilizing ability reflecting a compromise between the stabilizing effect of lone pair donation (which decreases both across and down the periodic table from nitrogen) and the concurrent destabilizing effect of $\sigma$ withdrawal (which increases across but decreases down the period table from nitrogen). Thus, the amine groups are the most stabilizing, followed by the thiyl groups, the hydroxy and alkoxy groups, the phosphines and finally the halogens. It is seen that the $\sigma$ donor substituent $\mathrm{BH}_{2}$ has a very large radical stabilizing effect, comparable to the strongest lone pair donors.

In general, the trends in the ${ }^{\bullet} \mathrm{CH}\left(\mathrm{CH}_{3}\right) \mathrm{X}$ and ${ }^{\bullet} \mathrm{C}\left(\mathrm{CH}_{3}\right)_{2} \mathrm{X}$ RSEs mirror those in the corresponding ${ }^{\circ} \mathrm{CH}_{2} \mathrm{X}$ radicals, though there are important exceptions. In particular, the inclusion of the additional electron-donating methyl substituents tends to stabilize the radicals and this stabilization is enhanced when $\mathrm{X}$ is an electron-accepting group such as carbonyl or thiocarbonyl derivative, or a fluorinated species. By contrast this stabilization effect is much less significant if $\mathrm{X}$ is lone pair $/ \pi$ donor group, and in some cases the steric cost of including 


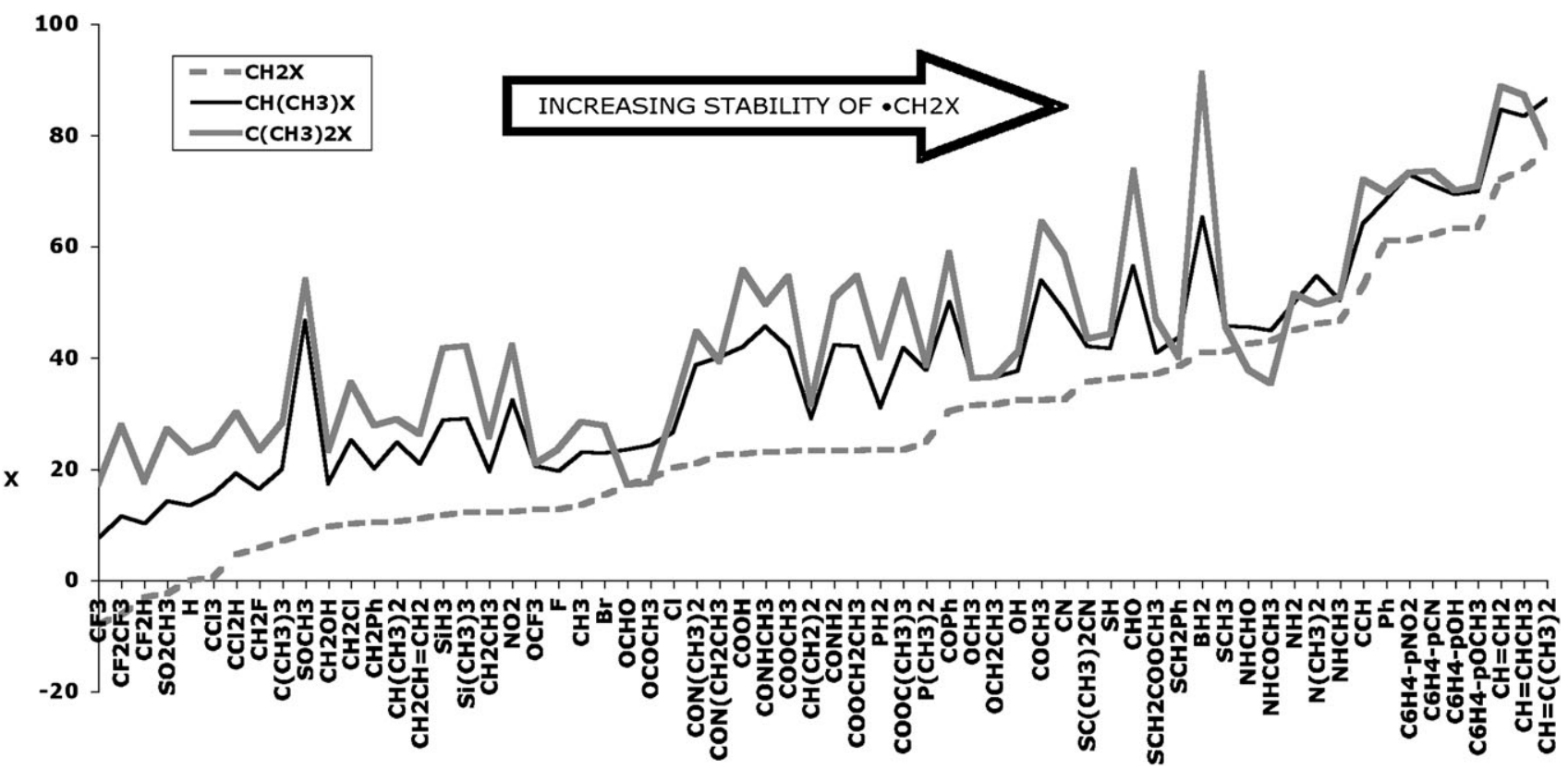

Fig. 6 Standard RSE values $\left(298 \mathrm{~K}, \mathrm{~kJ} \mathrm{~mol}^{-1}\right)$ for ${ }^{\bullet} \mathrm{CH}_{2} \mathrm{X},{ }^{\bullet} \mathrm{CH}\left(\mathrm{CH}_{3}\right) \mathrm{X}$ and ${ }^{\bullet} \mathrm{C}\left(\mathrm{CH}_{3}\right)_{2} \mathrm{X}$.

them leads to an overall destabilization of the radical. Interestingly, for the $\sigma$ donor group $\mathrm{BH}_{2}$, the inclusion of additional methyl groups in ${ }^{\bullet} \mathrm{CH}\left(\mathrm{CH}_{3}\right) \mathrm{BH}_{2}$, and ${ }^{\bullet} \mathrm{C}\left(\mathrm{CH}_{3}\right)_{2} \mathrm{BH}_{2}$, has a large stabilizing effect on radical stability, presumably because the $\sigma$ electron donation is not competing with the hyperconjugative stabilization of the methyl groups.

\section{Conclusion}

In this work we have examined some of the leading schemes used to measure relative radical stability, including the standard radical stabilization energy (RSE), ${ }^{3}$ and two alternative schemes, which we denote as $\mathrm{RSE}_{\mathrm{Z}}{ }^{17}$ and $\mathrm{RSE}_{\mathrm{V}}{ }^{19}$ respectively, that are based on corrected bond energies for other types of bonds. We have also evaluated them for a test set of 192 primary, secondary and tertiary carbon-centred radicals, presenting in the course of this work a new complete test set of their corresponding $\mathrm{R}-\mathrm{H}, \mathrm{R}-\mathrm{Cl}, \mathrm{R}-\mathrm{CH}_{3}$ and $\mathrm{R}-\mathrm{R}$ bond dissociation energies (BDEs), as calculated at the G3(MP2)RAD level of theory. In general we find that all schemes yield the same qualitative (and to a large extent the same quantitative) trends in the relative radical stabilities of our large test set, despite being based on very different bond energies and assumptions. They also show a high degree of correlation with the Mulliken spin densities on the nominal radical centre, a measure of the extent to which the substituents are capable of stabilizing the radical by delocalisation of an unpaired electron. The trends in the measured radical stabilization energies also follow the trends expected for the stabilities of the radical species, based on qualitative molecular orbital arguments. On this basis, we therefore conclude that these schemes all provide successful and consistent measures of intrinsic radical stabilities for simple carbon centred radicals, and should therefore be useful in predicting the stability and reactivity of these species beyond the reaction scheme for which they were measured. This is not to say that these schemes will necessarily be applicable for measuring relative radical stabilities of non-carbon centred radicals, and further work to explore their wider applicability is now underway.

\section{Acknowledgements}

We gratefully acknowledge financial support from the Australian Research Council under their Centres of Excellence program, and generous allocation of computing time on the National Facility of the National Computational Infrastructure. We also thank Professors Hendrik Zipse and Leo Radom for many useful discussions about radical stability.

\section{References}

1 D. Griller and K. Ingold, Acc. Chem. Res., 1976, 9, 13-19.

2 M. L. Coote and A. B. Dickerson, Aust. J. Chem., 2008, 61, 163-167.

3 S. W. Benson, Thermochemical Kinetics. Methods for the Estimation of Thermochemical Data and Rate Parameters, John Wiley \& Sons, New York, 1976.

4 Occasionally in the literature this sign convention has been reversed.

5 See, for example, H. Zipse, Top. Curr. Chem., 2006, 263, 163-189.

6 See for example: H. Fischer and L. Radom, Angew. Chem., Int. Ed., 2001, 40, 1340-1371.

7 C. Rüchardt, Angew. Chem., Int. Ed. Engl., 1970, 9, 830-843.

8 A. A. Zavitsas, J. Chem. Educ., 2001, 78, 417-419.

9 M. L. Coote, A. Pross and L. Radom, Org. Lett., 2003, 5, 4689-4692.

10 C. Rüchardt, Angew. Chem., Int. Ed. Engl., 1970, 9, 830-843.

11 S. J. Gronert, J. Org. Chem., 2006, 71, 1209-1219.

12 M. D. Wodrich and P. v. R. Schleyer, Org. Lett., 2006, 8, $2135-2138$.

13 K. U. Ingold and G. A. DiLabio, Org. Lett., 2006, 8, 5923-5925.

14 M. L. Poutsma, J. Org. Chem., 2008, 73, 8921-8928.

15 See for example: (a) C. Rüchardt and H.-D. Beckhaus, Top. Curr. Chem., 1985, 130, 1-22; (b) F. M. Welle, H.-D. Beckhaus and C. Rüchardt, J. Org. Chem., 1997, 62, 552-558.

16 G. Hellmann, S. Hellmann, H.-D. Beckhaus and C. Rüchardt, Chem. Ber., 1982, 115, 3364-3383. 
17 N. Matsunaga, D. W. Rogers and A. A. Zavitsas, J. Org. Chem., 2003, 68, 3158-3172.

18 L. Pauling, J. Am. Chem. Soc., 1932, 54, 3570-3582.

19 F. de Vleeschouwer, V. Van Speybroeck, M. Waroquier, P. Geerlings and F. de Proft, J. Org. Chem., 2008, 73, 9109-9120.

20 R. G. Parr, L. von Szentpaly and S. B. Liu, J. Am. Chem. Soc., 1999, 121, 1922.

21 F. de Vleeschouwer, V. Van Speybroeck, M. Waroquier, P. Geerlings and F. de Proft, Org. Lett., 2007, 9, 2721-2724.

22 See for example: D. R. B. Brittain, C. Y. Lin, A. T. B. Gilbert, E. I. Izgorodina, P. M. W. Gill and M. L. Coote, Phys. Chem. Chem. Phys., 2009, 11, 1138-1142, and references cited therein.

23 In the assessment study that accompanied ref. 19, the B3P86/ $6-311+G(d, p)$ level of theory used in this work had an MAD of $10.5 \mathrm{~kJ} \mathrm{~mol}^{-1}$ but a maximum error of $37.4 \mathrm{~kJ} \mathrm{~mol}^{-1}$.

24 J. J. Brocks, H.-D. Beckhaus, A. L. J. Beckwith and C. Rüchardt, J. Org. Chem., 1998, 63, 1935-1943.

25 (a) H. Fischer, Z. Naturforsch., A: Astrophys. Phys. Phys. Chem., 1964, 19, 855-867; (b) H. Fischer, Z. Naturforsch., A: Astrophys. Phys. Phys. Chem., 1965, 20, 428-432.

26 A number of the standard RSE values reported here have also recently appeared in the book chapter: M. L. Coote, C. Y. Lin and H. Zipse, in Carbon-Centered Free Radicals: Structure, Dynamics and Reactivity, ed. M. D. E. Forbes, Wiley, 2010, pp. 83-104.

27 M. J. Frisch, G. W. Trucks, H. B. Schlegel, G. E. Scuseria, M. A. Robb, J. R. Cheeseman, J. A. Montgomery Jr., T. Vreven, K. N. Kudin, J. C. Burant, J. M. Millam, S. S. Iyengar, J. Tomasi, V. Barone, B. Mennucci, M. Cossi, G. Scalmani, N. Rega, G. A. Petersson, H. Nakatsuji, M. Hada, M. Ehara, K. Toyota, R. Fukuda, J. Hasegawa, M. Ishida, T. Nakajima, Y. Honda, O. Kitao, H. Nakai, M. Klene, X. Li, J. E. Knox, H. P. Hratchian, J. B. Cross, C. Adamo, J. Jaramillo, R. Gomperts, R. E. Stratmann, O. Yazyev, A. J. Austin, R. Cammi, C. Pomelli, J. W. Ochterski, P. Y. Ayala, K. Morokuma, G. A. Voth, P. Salvador, J. J. Dannenberg, V. G. Zakrzewski, S. Dapprich, A. D. Daniels, M. C. Strain, O. Farkas, D. K. Malick, A. D. Rabuck, K. Raghavachari, J. B. Foresman, J. V. Ortiz, Q. Cui, A. G. Baboul, S. Clifford, J. Cioslowski, B. B. Stefanov, G. Liu, A. Liashenko, P. Piskorz, I. Komaromi, R. L. Martin, D. J. Fox, T. Keith, M. A. Al-Laham,
C. Y. Peng, A. Nanayakkara, M. Challacombe, P. M. W. Gill, B. Johnson, W. Chen, M. W. Wong, C. Gonzalez and J. A. Pople, Gaussian 03, Revision B.03, Gaussian, Inc., Pittsburgh, PA, 2003.

28 H.-J. Werner, P. J. Knowles, R. Lindh, F. R. Manby, M. Schütz, P. Celani, T. Korona, G. Rauhut, R. D. Amos, A. Bernhardsson, A. Berning, D. L. Cooper, M. J. O. Deegan, A. J. Dobbyn, F. Eckert, C. Hampel, G. Hetzer, A. W. Lloyd, S. J. McNicholas, W. Meyer, M. E. Mura, A. Nicklass, P. Palmieri, R. Pitzer, U. Schumann, H. Stoll, A. J. Stone, R. Tarroni and T. Thorsteinsson, MOLPRO, version 2006.6, a package of ab initio programs, see http://www.molpro.net.

29 (a) D. J. Henry, C. J. Parkinson, P. M. Mayer and L. Radom, J. Phys. Chem. A, 2001, 105, 6750-6756; (b) M. L. Coote, J. Phys. Chem. A, 2004, 108, 3865-3872; (c) E. I. Izgorodina, M. L. Coote and L. Radom, J. Phys. Chem. A, 2005, 109, 7558-7566; (d) E. I. Izgorodina, D. R. B. Brittain, J. L. Hodgson, E. H. Krenske, C. Y. Lin, M. Namazian and M. L. Coote, J. Phys. Chem. A, 2007, 111, 10754-10768; (e) C. Y. Lin, J. L. Hodgson, M. Namazian and M. L. Coote, J. Phys. Chem. A, 2009, 113, 3690-3697.

30 A. P. Scott and L. Radom, J. Phys. Chem., 1996, 100, $16502-16513$.

31 D. J. Henry, M. B. Sullivan and L. Radom, J. Chem. Phys., 2003, $118,4849-4860$

32 This program is freely available from http://rsc.anu.edu.au/ cylin/ scripts.html.

33 C. Y. Lin, E. I. Izgorodina and M. L. Coote, J. Phys. Chem. A, 2008, 112, 1956-1964.

34 See for example: E. Ruiz, J. Cirera and S. Alvarez, Coord. Chem. Rev., 2005, 249, 2649-2660, and references cited therein.

35 Y.-R. Luo, Comprehensive Handbook of Chemical Bond Energies, CRC Press, Boca Raton, FL, 2007.

36 For detailed molecular orbital based analyses of radical stabilities, see for example: (a) F. Bernardi, N. D. Epiotis, W. Cherry, H. B. Schlegel, M.-H. Whangbo and S. Wolfe, J. Am. Chem. Soc., 1976, 98, 469-478; (b) D. J. Henry, C. J. Parkinson, P. M. Mayer and L. Radom, J. Phys. Chem. A, 2001, 105, 6750-6756; (c) M. L. Coote and D. J. Henry, Macromolecules, 2005, 38, 1415-1433. 